Review

\title{
Carotenoids from Marine Microalgae: A Valuable Natural Source for the Prevention of Chronic Diseases
}

\author{
Maria Filomena de Jesus Raposo, Alcina Maria Miranda Bernardo de Morais, \\ and Rui Manuel Santos Costa de Morais *
}

CBQF - Centro de Biotecnologia e Química Fina—Laboratório Associado, Escola Superior de Biotecnologia, Universidade Católica Portuguesa/Porto, Rua Arquiteto Lobão Vital, Porto 4202-401, Portugal; E-Mails: fraposo@porto.ucp.pt (M.F.J.R.); abmorais@porto.ucp.pt (A.M.M.B.M.)

* Author to whom correspondence should be addressed; E-Mail: rcmorais@porto.ucp.pt; Tel.: +351-22-5580050; Fax: +351-22-5090351.

Academic Editor: Graziano Riccioni

Received: 5 July 2015 / Accepted: 3 August 2015 / Published: 14 August 2015

\begin{abstract}
Epidemiological studies have shown a relation between antioxidants and the prevention of several chronic diseases. Microalgae are a potential novel source of bioactive molecules, including a wide range of different carotenoids that can be used as nutraceuticals, food supplements and novel food products. The objective of this review is (i) to update the research that has been carried out on the most known carotenoids produced by marine microalgae, including reporting on their high potentialities to produce other less known important compounds; (ii) to compile the work that has been done in order to establish some relationship between carotenoids and oxidative protection and treatment; (iii) to summarize the association of oxidative stress and the various reactive species including free radicals with several human diseases; and (iv) to provide evidence of the potential of carotenoids from marine microalgae to be used as therapeutics to treat or prevent these oxidative stressrelated diseases.
\end{abstract}

Keywords: carotenoids; marine microalga; astaxanthin; $\beta$-carotene; fucoxanthin; ROS; RNS; free radicals; oxidative stress; inflammatory diseases; chronic diseases; aging 


\section{Introduction}

Changes in lifestyle and nutrition, stress most people are submitted to, growing levels of pollution, exposure to xenobiotics and radiation that has been increasing for the last decades, and even an excess of physical exercise may all be responsible for several metabolic diseases. These factors can cause changes in the metabolism, increasing the cellular respiration rate and inducing an imbalance between the oxidation products generated and the natural antioxidant capacity of the cells. During the normal metabolism, mainly along the respiratory chain in the mitochondria, some free radicals and reactive species, either from oxygen (ROS) or nitrogen (RNS), but also proteins and lipids, are naturally elicited to suffer (per)oxidation. DNA can be a target as well, leading to genome instability and increasing the risk of molecular change and mutations. All these changes may cause damage in the cell metabolism, disease and even death. It is known that ROS are associated with a wide range of diseases, such as aging, Alzheimer, Parkinson, atherosclerosis, cardiovascular disease (CVD), cancer, inflammatory and neurological diseases, diabetes and obesity, amongst others [1-3]. RNS are also involved in the peroxidation of lipids and nitration of proteins, as well as in the formation of many other reactive species, such as malondialdehyde (MDA), a marker of oxidative stress.

As with mitochondria, cell organelles that are very vulnerable to oxidative stress due to the high concentration of oxygen $\left(\mathrm{O}_{2}\right)$, the brain and the central nervous system (CNS) are also susceptible to lipid/fatty acid peroxidation induced by ROS, because of the high pressures of $\mathrm{O}_{2}$ and oxidation reactions. This may be the main reason why neurodegenerative diseases-Alzheimer, Parkinson, amyotrophic lateral sclerosis, amongst others - are strictly associated with oxidative damage and/or deficiency of endogenous oxidative protection in the cells of the nervous system [4]. Using a simple but clarifying scheme, Kalam et al. [4] have synthesized the whole process starting with the formation of free radicals, ROS and RNS, and continuing on through the protective responses of antioxidants (AO) and the effects of oxidative stress on various macromolecules, which lead to a wide range of chronic diseases. Another organ susceptible to being attacked by ROS are the lungs, as they are also exposed to a high concentration of $\mathrm{O}_{2}$ and radicals and other reactive species originating from pollutants like cigarette smoke, such as $\mathrm{O}_{2}{ }^{--}$and $\mathrm{NO}$, which trigger oxidative chain reactions [5].

However, some of the free radicals and reactive species that result from the cellular metabolism, are effective/beneficial in moderate concentrations in regulating the intracellular redox signaling [3], fighting the invasion of organisms and inflammation by pathogens [6], or even inducing the cells to adapt themselves and protect from other severe oxidative damages. For example, they may create tolerance to ischemic-induced conditions [7]. When this equilibrium is broken and reactive species surpass the capacity of endogenously-induced anti-oxidative protection of cells, the imbalance induces damage by oxidative stress, and regular physiological functions of proteins, lipids, DNA or other important biocompounds become impaired, triggering the pathogenesis of several diseases.

Carotenoids in general, and those from marine microalgae in particular, are excellent antioxidants, which can be exogenously supplied to the cells, re-establishing the levels of oxidative stress (OS) and nitrogen stress (NS) by neutralizing the excess of free radicals and reactive species. Some of the most known and studied carotenoids produced by microalgae include $\beta$-carotene from Dunaliella salina, astaxanthin from Haematococcus pluvialis, canthaxanthin from Coelastrella striolata, but also the less 
known, but not less effective, fucoxanthin from several diatoms, such as Phaeodactylum tricornutum, and Isochrysis galbana (Table 1).

Several studies have already been published reporting the association of carotenoids-antioxidant properties with protection against several malfunctions and diseases triggered by oxidative stress [8-15], but only a few references have dealt with carotenoids from marine microalgae [6,16-21], and even fewer studies relate to the beneficial effects of microalgal carotenoids in humans [22-26].

This review will focus on the microalgae producing the various carotenoids, their cumulative concentrations and the known biosynthesis pathways of carotenoids in microalgae. The antioxidant capacity of the different carotenoids against the various radicals and reactive species will also be discussed, as well as the benefits of using marine carotenoids (or microalgae biomass) to neutralize the oxidative stress, as this may trigger several diseases.

\section{Carotenoids from Marine Microalgae}

Several kinds of carotenoids are produced by marine microalgae (Table 1). Most of them have been clearly quantified, but sometimes only the percentage of the total carotenoid yield is known. Many other carotenoids have been reported to be constituents of a given microalga, but there in these cases, no reference is made regarding their concentration [27,28].

According to their structure, carotenoids can be classified into different groups. Carotenes ( $\alpha$ - and $\beta$-carotenes (D. salina), and lycopene) do not have any substituent (or even oxygen) in their structure, they are strict hydrocarbon carotenoids; xanthophylls or oxycarotenoids present $-\mathrm{OH}$ groups (hydroxycarotenoids: zeaxanthin from $P$. cruentum, lutein from C. pyrenoidosa), $=\mathrm{O}$ groups (ketocarotenoids: canthaxanthin from C. striolata), echinenone from B. braunii, S. platensis), or both $-\mathrm{OH}$ and $=\mathrm{O}$ groups (astaxanthin from $H$. pluvialis) (Table 1$)$. In addition, some other carotenoids have more complex structures, such as violaxanthin $(C$. ellipsodea $)$ and diadinoxanthin (P. tricornutum) with epoxy groups, and dinoxanthin and fucoxanthin (I. galbana) with acetylated groups. These last two acetylated carotenoids, which can be found in diatoms, haptophytes and dinophytes [29], present the curious structure $\mathrm{C}=\mathrm{C}=\mathrm{C}$ (allene), unique to natural products [30]. A more curious structure, acetylene or $\mathrm{C} \equiv \mathrm{C}$, is also part of some carotenoids (all-, diato-, diadino-, hetero-, croco-, pyro- and monadoxanthin); these acetylenic carotenoids can be typically found in some groups of microalgae, such as the cryptophytes, diatoms, haptophytes, euglenophytes and dinophytes [29]. Some new carotenoids have been identified in B. braunii (Table 1).

Another curiosity is the fact that only two carotenoids have been found in the red marine microalga $P$. cruentum: zeaxanthin (making up $97.4 \%$ of the total carotenoids) and $\beta$-carotene (with only $2.6 \%$ ) (Table 1 ). 
Table 1. Main carotenoids from marine microalgae.

\begin{tabular}{|c|c|c|c|c|c|c|}
\hline Main Carotenoid & $\begin{array}{c}\text { Chemical IUPAC Name/ } \\
\text { Chemical Structure } \\
\end{array}$ & Concentration & Microalga & Other Carotenoids & Remarks & References \\
\hline \multirow[t]{3}{*}{$\beta$-carotene } & $\beta, \beta$-carotene & $10 \%-13 \% \mathrm{DW}$ & Dunaliella salina & $\begin{array}{c}\text { zeaxanthin, lutein, } \\
\alpha \text {-carotene } \\
\end{array}$ & $\begin{array}{l}\text { occur mostly as a mixture of 9-cis and } \\
\text { all-trans, but also other cis isomers }\end{array}$ & \multirow{3}{*}{ [31-37] } \\
\hline & & $50 \% \mathrm{TC}(\mathrm{TC}=0.9 \% \mathrm{DW})$ & Chlorella zofingiensis & $\begin{array}{c}\text { canthaxanthin }(25 \% \mathrm{TC} \text { or } 97 \% \mathrm{DW}) \text {, } \\
\text { astaxanthin }(0.7 \% \mathrm{DW})\end{array}$ & & \\
\hline & & $80 \% \mathrm{TC}$ & Arthrospira & $\begin{array}{c}\text { astaxanthin, lutein } \\
\beta \text {-cryptoxanthin, zeaxanthin, } \\
\text { echinenone, oscillaxanthin, } \\
\text { myxoxanthophyll }\end{array}$ & & \\
\hline \multirow[t]{2}{*}{$\begin{array}{l}\text { astaxanthin } \\
\text { (as } 3 S, 3^{\prime} S \text { isomer) }\end{array}$} & $\begin{array}{c}\text { 3,3'-dihydroxy- } \beta, \\
\beta \text {-carotene-4,4'-dione }\end{array}$ & up to $7 \% \mathrm{DW} ; 75 \% \mathrm{TC}$ & $\begin{array}{c}\text { Haematococcus } \\
\text { pluvialis }\end{array}$ & $\begin{array}{c}\beta \text {-carotene, lutein, canthaxanthin, } \\
\text { neoxanthin, violaxanthin, } \\
\text { zeaxanthin, echinenone }\end{array}$ & $\begin{array}{l}\text { occur as a racemic mixture of mainly } \\
\text { mono- and diesters } \\
(c a .73 \% \mathrm{TC}), \text { but also as free } \\
\text { astaxanthin }\end{array}$ & {$[21,38-42]$} \\
\hline & $\begin{array}{c}\beta, \varepsilon \text {-carotene- } 3,3^{\prime} \text {-diol } \\
\mathcal{O}^{\circ}{ }^{\circ}\end{array}$ & $0.2 \%-0.4 \% \mathrm{DW}$ & C. pyrenoidosa & $\begin{array}{l}\text { violaxanthin, loroxanthin, } \\
\qquad \alpha \text { - and } \beta \text {-carotene }\end{array}$ & & [43] \\
\hline canthaxanthin & $\begin{array}{c}\beta, \beta \text {-carotene- } 4,4^{\prime} \text {-dione } \\
0\end{array}$ & $4.75 \% \mathrm{DW}$ & $\begin{array}{c}\text { Coelastrella striolata } \\
\text { var. multistriata }\end{array}$ & $\begin{array}{c}\text { astaxanthin } 0.15 \% \mathrm{DW}, \\
\beta \text {-carotene } 0.7 \% \mathrm{DW}\end{array}$ & & [37] \\
\hline $\begin{array}{c}\text { canthaxanthin } \\
\text { lutein }\end{array}$ & $\begin{array}{c}\beta, \beta \text {-carotene- } 4,4^{\prime} \text {-dione } \\
\beta, \varepsilon \text {-carotene-3,3'-diol }\end{array}$ & $45 \% \mathrm{TC}$ & C. vulgaris & $\begin{array}{c}\text { astaxanthin } 12.5 \% \mathrm{TC} \\
\text { violaxanthin }\end{array}$ & & {$[44,45]$} \\
\hline
\end{tabular}


Table 1. Cont.

\begin{tabular}{|c|c|c|c|c|c|c|}
\hline \multirow[t]{3}{*}{ fucoxanthin } & \multirow{4}{*}{$\begin{array}{c}\text { acetic acid }[(1 S, 3 R) \text {-3-hydroxy-4- } \\
{[(3 E, 5 E, 7 E, 9 E, 11 E, 13 E, 15 E) \text {-18-[(1S,4S,6R)-4- }} \\
\text { hydroxy-2,2,6-trimethyl-7- } \\
\text { oxabicyclo[4.1.0]heptan-1-yl]-3,7,12,16- } \\
\text { tetramethyl-17-oxooctadeca-1,3,5,7,9,11,13,15- } \\
\text { octaenylidene]-3,5,5-trimethylcyclohexyl] ester }\end{array}$} & $1.65 \% \mathrm{DW}$ & P. tricornutum & \multirow[t]{2}{*}{$\begin{array}{l}\text { diadinoxanthin, eaxanthin, } \\
\text { neoxanthin, violaxanthin, } \\
\beta \text {-carotene }\end{array}$} & \multirow[t]{2}{*}{$\begin{array}{c}\text { occur mainly as all-trans } \\
\text { but also as cis isomers }\end{array}$} & \multirow{2}{*}{$\begin{array}{r}{[46-48]} \\
{[49]} \\
\end{array}$} \\
\hline & & $1.8 \% \mathrm{DW}$ & Isochrysis aff. galbana & & & \\
\hline & & $0.52 \% \mathrm{DW}$ & $\begin{array}{c}\text { Cylindrotheca } \\
\text { closterium }\end{array}$ & & & {$[50]$} \\
\hline \multirow[b]{2}{*}{ zeaxanthin } & & up to $2.2 \% \mathrm{DW}$ & Odontella aurita & diadinoxanthin, $\beta$-carotene & & [51] \\
\hline & $\beta, \beta$-carotene-4,4'-diol & $97.4 \% \mathrm{TC}$ & P. cruentum & $\beta$-carotene & & {$[52]$} \\
\hline $\begin{array}{l}\text { echinenone } \\
\text { (extracelular) }\end{array}$ & $\beta, \beta$-carotene-4-one & $0.17 \% \mathrm{DW}$ & B. braunii & $\begin{array}{l}\text { botryoxanthins } \mathrm{A} \text { and } \mathrm{B}-0.03 \% \\
\text { DW } \\
\text { braunixanthins } 1 \text { and } 2-0.06 \% \\
\text { DW }\end{array}$ & $\begin{array}{l}\text { extracellular pigments are produced and } \\
\text { secreted into the intercellular matrix }\end{array}$ & {$[53]$} \\
\hline Lutein (intracelular) & $\beta, \varepsilon$-carotene- $3,3^{\prime}$-diol & up to $0.16 \% \mathrm{DW}$ & & $\begin{array}{c}\text { neox/loroxanthin } 0.042 \% \mathrm{DW} \\
\alpha \text { - and } \beta \text {-carotene } 0.031 \% \mathrm{DW} \\
\text { violaxanthin } 0.02 \% \mathrm{DW} \\
\end{array}$ & & \\
\hline 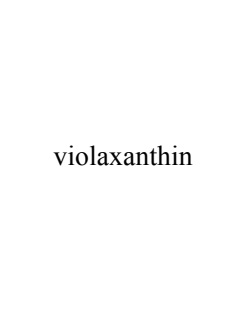 & $\begin{array}{c}(1 S, 4 S, 6 R)-1- \\
{[(1 E, 3 E, 5 E, 7 E, 9 E, 11 E, 13 E, 15 E, 17 E)-18-} \\
{[(1 S, 4 S, 6 R)-4 \text {-hydroxy-2,2,6-trimethyl-7- }} \\
\text { oxabicyclo[4.1.0]heptan-1-yl]-3,7,12,16- } \\
\text { tetramethyloctadeca-1,3,5,7,9,11,13,15,17- } \\
\text { nonaenyl]-2,2,6-trimethyl-7-oxabicyclo[4.1.0] } \\
\text { heptan-4-ol }\end{array}$ & & C. ellipsodea & antheraxanthin, zeaxanthin & & {$[45]$} \\
\hline
\end{tabular}


The biosynthesis of isopentenyl pyrophosphate (IPP) may usually be explained by one of two different pathways (Figure 1): the mevalonate pathway (MVA) in euglenophytes and 1-deoxy-D-xylulose-5-phosphate pathway (DOXP) in Chlorophyceae and Cyanophyceae [54,55].

Based on Takaichi [29] and Han et al. [27], Figure 1 summarizes the carotenogenesis pathways for eukaryotic microalgae, assuming the DOXP pathway for IPP synthesis (Figure 1) and the scheme indicated by Takaichi [29] for the pathways in cyanobacteria. Some known genes and the enzymes they code for have been isolated from different species of microalgae and cyanobacteria, and their functions have been conveniently identified and presented in recent reviews [27,29].

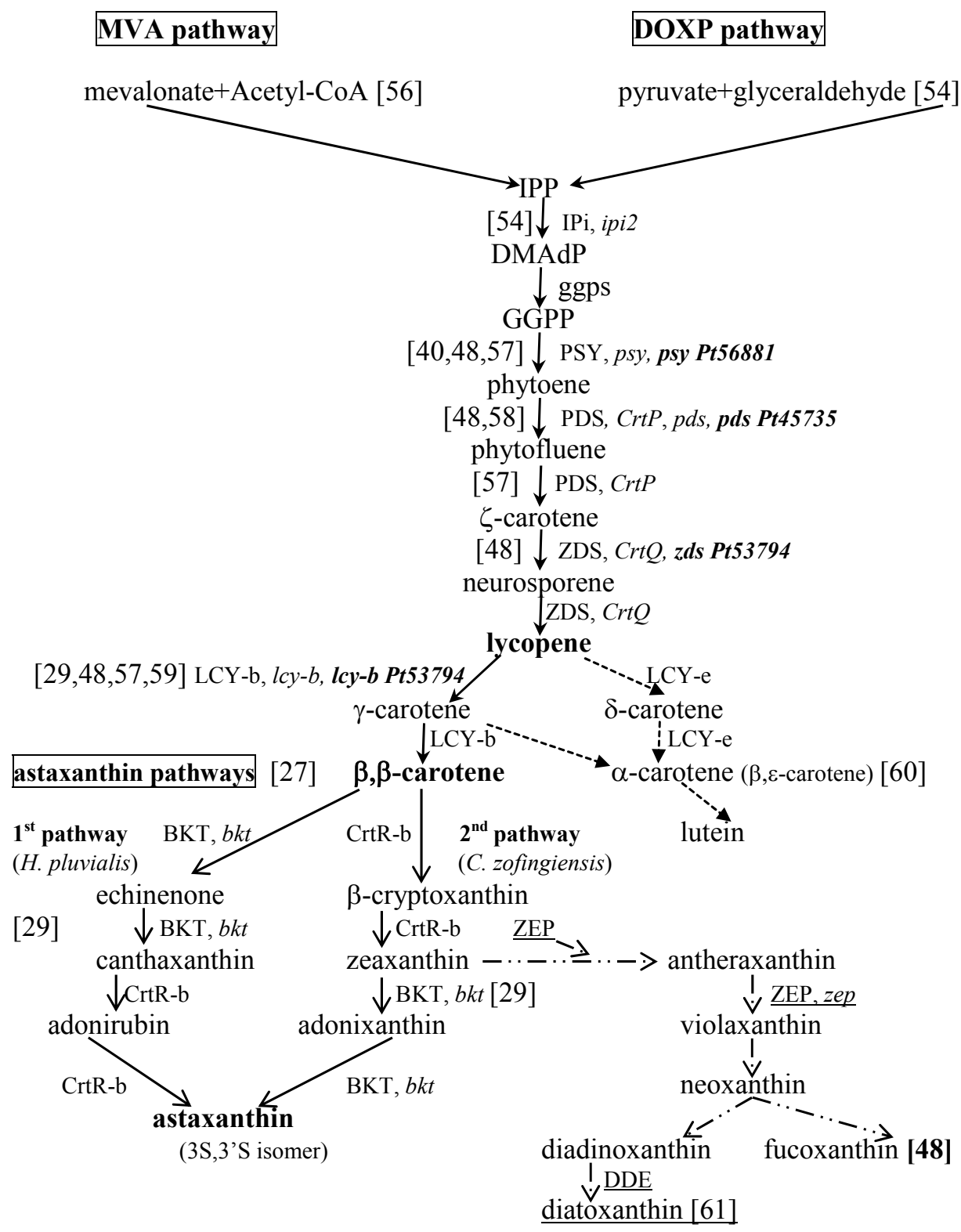

Figure 1. Pathways for the carotenogenesis and biosynthesis of astaxanthin, based on Han et al. [27], Dambek et al. [48] and Takaichi [29], and the synthesis of fucoxanthin and diadinoxanthin in diatoms [61], including P. tricornutum, proposed by Dambek and colleagues [48]. The genes and enzymes involved in the process and already identified in some microalgae are evidenced; the underlined ones were reported by Bertrand [61]. 
Concerning the derivatives of either $\beta$ - and $\alpha$-carotene, most of the steps indicated for the full process of the carotenogenesis pathway in algae have been proposed by establishing some relations among the chemical structures of carotenoids [29]. However, the real pathways and enzymes involved still need to be studied and explained.

\section{Oxidative Stress-The Importance of Reactive Species in Aging and Age-Related Diseases}

Once initiated, the propagation of (per)oxidative reactions, spread out by the reaction of the new formed products or free radicals with other chemical species, including peroxyl and alkoxyl radicals, which in turn can go on attacking lipids and other biomolecules. For example, peroxynitrite, the product of the reaction between superoxide anion radicals and nitric oxide can generate, in the presence of lipid hydroperoxides, an oxygen singlet (Figure 2), which is another reactive species (not a free radical) able to cause severe modifications in amino acids and/or proteins [62].

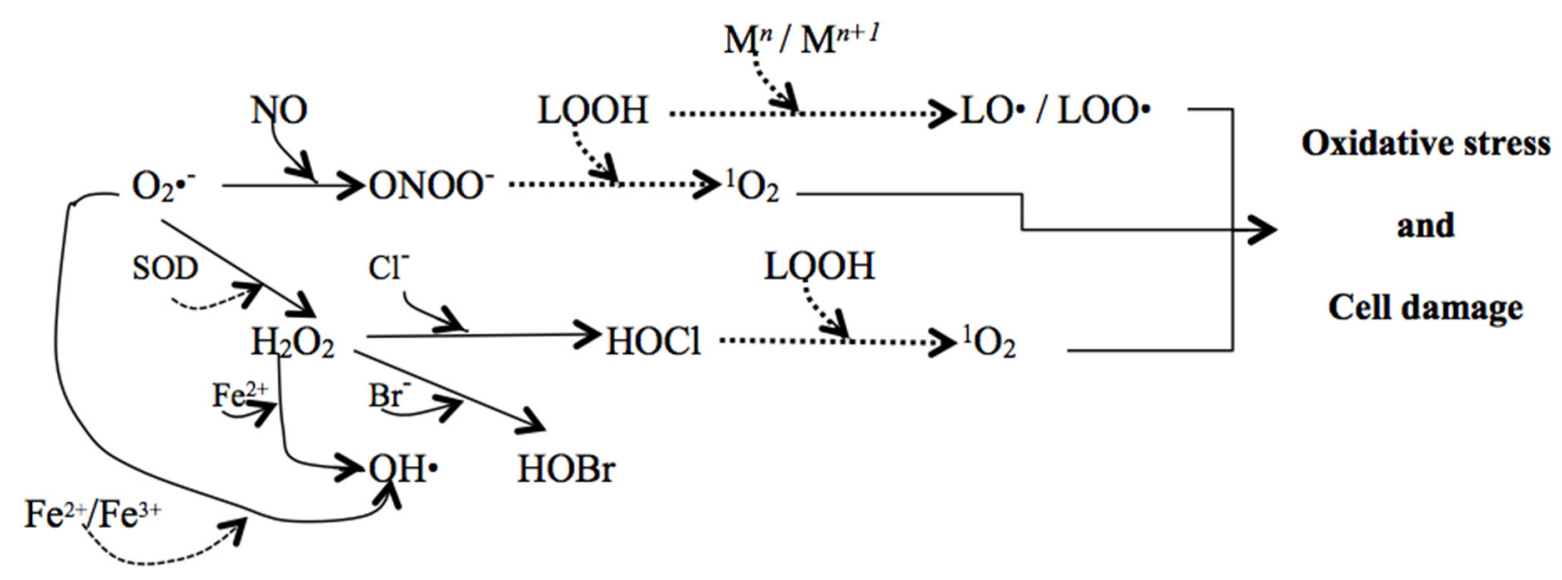

Figure 2. Cascade triggered within a cell by $\mathrm{O}_{2}{ }^{--}$(superoxide radical) generated mainly by NADPH oxidase. Some reactions with lipid hydroperoxides (LOOH) are also included (dashed arrows; $\mathrm{M}=$ transition metal) [58,63-65].

Free radicals are generated during cell metabolism, and their levels may be increased by pro-oxidants. They need to receive an electron to pair with the unpaired electron. When these important chemical reactive species are overproduced in vivo they can cause an imbalance between ROS and RNS and their elimination by the endogenous AO, including enzymes (catalase, for example) and glutathione (GSH), which are part of the cell defense mechanisms [4]. The oxidative stress generated will induce the chain oxidation reactions, causing cell damage and aging, and, therefore, inducing several diseases, including cancer $[66,67]$.

However, ROS and RNS have addition beneficial effects that are strictly related to cell signaling and the immune system, i.e., to supply energy and to get rid of toxins [68], a major role they play when they are present in small amounts. When this redox equilibrium is broken, ROS can attack lipids, proteins and DNA, forming lipid radicals, amino and thiyl radicals, and sugar- and base-derived radicals that, in turn, can be oxidized into peroxyl radicals (Table 2) [4]. Kalam et al. [4] have simply and clearly described the (per)oxidation chain reactions starting with the attack of ROS on various essential biomolecules, especially lipids, continuing on to the formation of lipid hydroperoxydes and 
peroxyradicals, and subsequently generating aldehydes. Some of the newly formed radicals can be scavenged by the endogenous AO, but others can feed the oxidative chain reaction.

Table 2. Reactive species causing oxidative stress.

\begin{tabular}{cc}
\hline Groups of Reactive Species & Examples \\
\hline ROS & $\mathrm{O}_{2}{ }^{-{ }^{-}}, \mathrm{H}_{2} \mathrm{O}_{2}, \mathrm{HO} \cdot, \mathrm{O}_{2}, \mathrm{O}_{3}$ \\
RNS & $\mathrm{NO}, \mathrm{ONOO}^{\circ}, \mathrm{NO}_{2}{ }^{-}$ \\
Lipid hydroperoxides & $\mathrm{LO}, \mathrm{LOO}$ \\
RCS & $\mathrm{HOCl}, \mathrm{HOBr}$ \\
Glycoxidative species & AGE, ALE \\
Others: & Carbonyl radicals, RSS, GS \\
\hline
\end{tabular}

$\mathrm{RCS}=$ reactive chlorous/bromous species; $\mathrm{RSS}=$ reactive sulfur species; $\mathrm{GS}^{\bullet}=$ glutathione thiyl radical.

Moreover, the reactive aldehydes, such as MDA, hydroxynonenal (4-HNE) and acrolein (ACR), and lipid hydroperoxides seem to play a concentration-dependent dual role in the cell metabolism [62]. On the one hand, they can show protective functions by acting as signaling molecules and stimulating gene expression or neutralizing peroxidative damages by reducing themselves while receiving two electrons [62]. On the other hand, as they are highly reactive and toxic, these reactive species may be reduced by receiving one electron, initiating the lipid peroxidation cascade [69] and causing considerable damage in the cells, sometimes even leading to death [62]. These reactive species can also inhibit gene expression, and they play an important role in neurodegenerative diseases. This dual role depends on the cellular levels and cell types of the reactive aldehydes: They may present some oxidative protection in spite of eventually inducing some cell damage with which cells can survive and subsist, or they may cause severe effects leading to the development of several diseases [62]. Compared to free radicals, these aldehydes are relatively stable and can be more dangerous than ROS as they can exert their action away from the place where they were formed [70], whilst oxygen radicals are short-live species that attack in the surroundings of the site of production [71]. Nevertheless, these can also be dangerous. In fact, HO', which is able to start lipid peroxidation close to the site of origin, generating LOO ${ }^{\circ}$ radicals, is a very reactive species [6].

Ayala and colleagues have recently [62] and extensively given an overview of the relationship between oxidative stress and disease; they present simple but clarifying schemes to elucidate the mechanisms of lipid peroxidation, especially MDA and 4-HNE formation and metabolism.

Oxidative stress has also been associated with the formation of atheromas that can lead to cardiovascular diseases [3,72,73], including thrombosis after rupture of atherosclerotic plaques. Overproduction of free radicals is another feature at the origin of pathological inflammation [3]. By using simple schemes, Pashkow [3] has explained the onset of CVD, starting with oxidative stress, which greatly interferes with the regular function of platelets. These cell particles release more NO, a reactive element that induces an increase of the thrombus due to platelets aggregation. A treatment with a ROS scavenger has been suggested to inhibit such platelet behavior, thus stimulating their disaggregation. Furthermore, diabetic cardiomyopathy, congestive cardiomyopathy and hypertension-related heart disease were some of the diabetic complications arising from oxidative stress that were given in the overview by Pashkow [3]. 
Klaunig et al. [74] are another group that worked on the link between oxidative damage and disease, namely carcinogenesis. They suggested that the increase in number and size of peroxisomes (cell organelles), which are induced by hypolipidemic drugs and other substances, may be associated to liver cancer [75]. This may be explained by an increase of the peroxisomal enzymes acyl-CoA and xanthine oxidase (XO) induced by oxidative stress that enhances the production of ROS, such as $\mathrm{H}_{2} \mathrm{O}_{2}$ and $\mathrm{O}_{2}{ }^{-{ }^{-}}$.

Another reason for the association of oxidative stress with disease is the fact that F2 Isoprostanes (e.g., 8 -iso-PGF $2 \alpha$ ) are biomarkers associated with lipid peroxidation. They are indicators of the presence of diabetes 1 and 2 in the urine [76]. The formation of these substances and the subsequent increase of thiobarbituric acid reactive species (TBARS) (Table 3) can be inhibited by the endogenous superoxide dismutase (SOD) and butylated hydroxy-toluene (BHT) [77]. Perhaps, a similar response might be obtained by using carotenoids, as they, or at least some of them, are able to neutralize oxygen free radicals (Table 4). Moreover, oxidative stress has been associated with hyperglycemia for decades [73,78,79]. Mezzetti and colleagues [76] have concisely established various links between the different sources of oxidative stress and the associated biomarkers (Table 3), which also appear in higher levels in plasma and/or urine of diabetics and patients with related complications, such as atherosclerosis.

Additionally, in diabetics for example, the autoxidation of sugars, plasma unsaturated lipids and proteins from cell membranes, and the reactions between sugars and proteins produce free radicals, which may be the cause of oxidative stress and damage. Baynes [8] established some relationships between oxidative stress and the subsequent effects/damages in diabetic patients. He described some sources of oxidative stress, and suggested some therapeutical treatments using antioxidants and anti-inflammatory agents, other than carotenoids, to reduce the effects of oxidized lipoproteins and lipid peroxides. These relationships may explain the (per)oxidative and inflammatory processes as triggering the initial steps of diabetes, but also complications derived from the development of the disease itself. This type of therapeutics can be used to break down the chain-production of free radicals [8] as well. Baynes [8] also reviewed the reactions that may lead to atherosclerosis, as a complication generated by the oxidation of lipids and lipoproteins in diabetics. Some biomarkers for oxidative stress (Table 3 ) in these patients were given as well, as some of those glycative and/oxidative products (Table 3) are unique and stable.

In addition, one of the theories on aging claims that it might result from damaged tissues caused by reactive species, such as free radicals that are generated during the consumption of oxygen by mitochondria. During aerobic respiration, the agents responsible for the AO defense are overwhelmed by these ROS and an imbalance is created. By using the right natural carotenoids, including those from marine microalgae, at the corrected doses, the levels of such reducing agents would be expected to improve, restoring the endogenous antioxidative system in the cells [80].

Furthermore, according to Kalam and co-workers [4], it seems that the initiation process in chronic diseases is always associated with the overproduction of reactive species (e.g., ROS), which mediate the initial steps of inflammation that leads to carcinogenesis, directly by the oxidation, nitration or halogenation of lipids or nucleic acids, or indirectly by activating the signaling pathways. 
Table 3. Main biomarkers of oxidative stress.

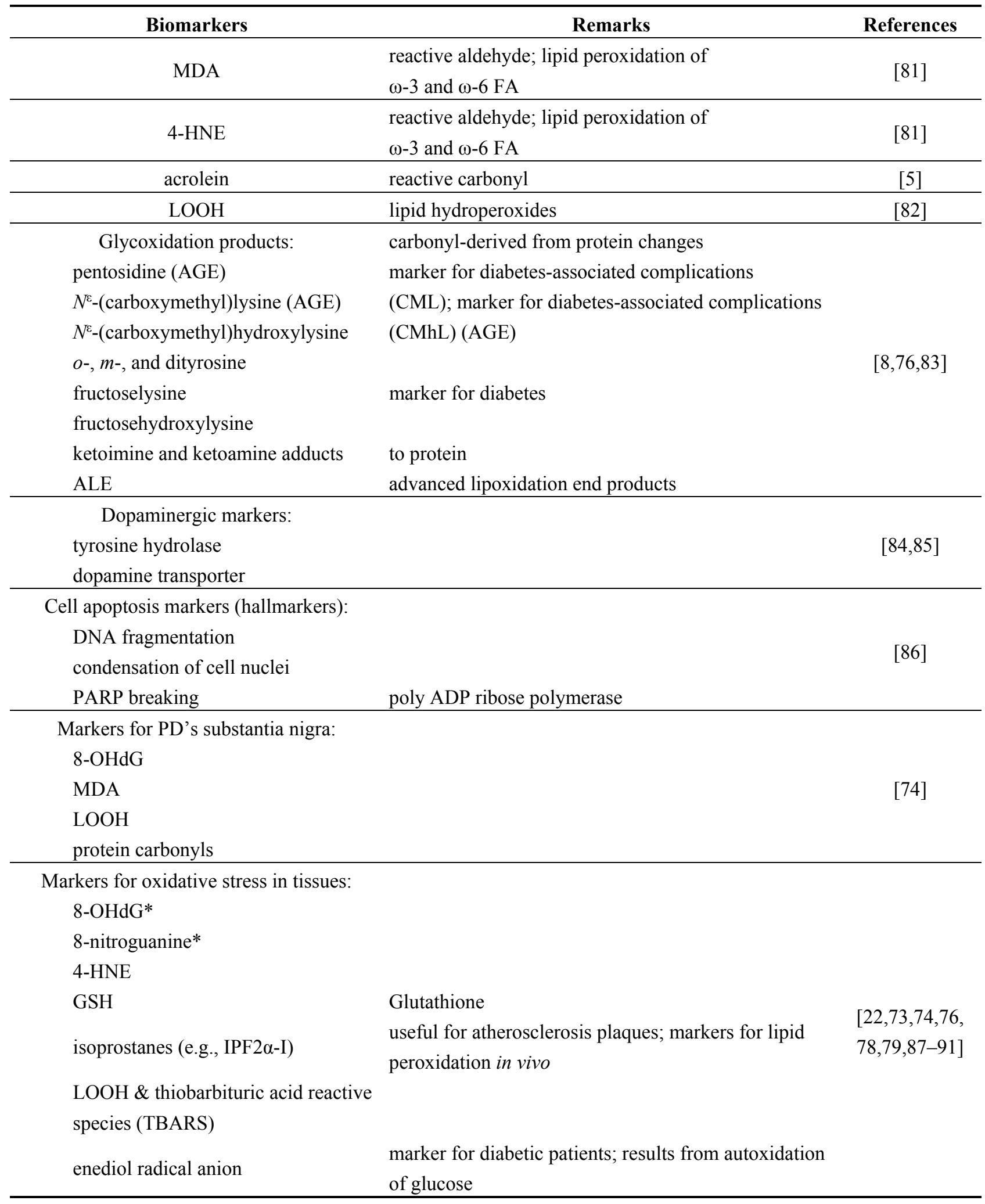

* useful for DNA lesions and human cancers. 


\section{Carotenoids from Marine Microalgae against Oxidative Stress}

\subsection{Uptake and Bioavailability}

Most carotenoids cross the cell membrane by simple or facilitated diffusion [92-95] and are delivered through the body as a part of lipoproteins [93-97]. All-trans and 9-cis forms of $\beta$-carotene are mainly accumulated in chylomicrons and VLDL, respectively [98], and xanthophylls in LDL and HDL [99,100]. However, astaxanthin appears mostly in VLDL-containing chylomicrons [101], and lutein and zeaxanthin are found to be preferably absorbed into chylomicrons [102].

According to several groups of researchers, carotenoids are better available if administered along with some kinds of fat, such as phospholipids or special edible oils $[26,92,103,104]$ as the vehicle, since carotenoids are better absorbed into chylomicrons at the intestine level. From here they are delivered to the cells of the individuals/animal models, where they seem to be especially integrated into the mitochondria [86,96,105], but also into nuclei and microsomes [96]. However, different carotenoids seem to be absorbed differently. For example, fucoxanthin has been found to being better absorbed than lutein or astaxanthin, the metabolites of these being found in higher concentrations in mice [106,107]. Furthermore, these metabolites, fucoxanthinol, amarouciaxanthin $\mathrm{A}$ and halocynthiaxanthin, have already been identified in several animal models and cell-lines [108-111]. Some studies have even suggested a better bioavailability of fucoxanthinol than fucoxanthin [112], and have reported that the former is converted into amarouciaxanthin A in the liver [103]. Additionally, no fucoxanthin has been found in the liver and plasma [110,113], but fucoxanthinol and amarouciaxanthin have been detected in several tissues [107]. More recently, Rao and co-workers [114] found that astaxanthin, $\beta$-carotene and lutein from different microalgae appeared mainly in the liver, with astaxanthin being preferentially absorbed; this carotenoid also showed a higher AO capacity by increasing catalase, SOD and peroxidase to higher levels and by preventing in vivo lipid peroxidation. Additionally, astaxanthin demonstrated to be better available and accumulated in larger amounts than lutein and $\beta$-carotene in a rat-model. It is worth noting though that in this study [114], the results among different groups of animals could have been influenced by other compounds of the microalgal biomass, since the various carotenoids were administered as being part of referred biomass from $H$. pluvialis, S. platensis and B. braunii. In addition, natural carotenoids already have been shown to be better available than synthetic ones [115], and the availability is also improved if carotenoids are taken after meals [116]. Furthermore, Régnier et al. [21] found that a natural racemic mixture of astaxanthin extracted with solvents presented twice as much antioxidative protection as that extracted by supercritical methods; this protection was almost five times higher (in vitro tests) than that of synthetic astaxanthin, which presented even lower activity than astaxanthin obtained by supercritical methods. However, when AO activity of various extracts were tested in Human Umbilical Vein Endothelial Cells (HUVEC) cells, the antioxidative cell protection was almost 90 times higher with the natural astaxanthin containing esters than with the synthetic xanthophyll [21], thus contributing to the cells' defense against oxidative stress. Regarding astaxanthin, the geometrical isomer $3 S, 3^{\prime} S$ was more readily absorbed despite being in a lower concentration in a racemic mixture, and cis $(Z)$ forms were selectively absorbed [117], especially $13 Z$ isomers [101]. 


\subsection{Antioxidant Protection}

In the near future, unicellular microalgae might be an alternative source to obtain AO because their carotenoids (Table 4), phenolics and other bioactive compounds, such as vitamins, fatty acids and polysaccharides, act synergistically towards their AO properties, which may be of some usefulness against oxidative damage [118].

Table 4. Antioxidant activity of main carotenoids from microalgae against reactive species.

\begin{tabular}{|c|c|c|c|}
\hline Carotenoid & AO activity & Reactive Species & References \\
\hline astaxanthin & $\begin{array}{c}{ }^{1} \mathrm{O}_{2} \text { quencher, } \\
\text { radical scavenging, } \\
\text { ROS and RNS quencher, } \\
\text { chain-breaking AO, } \\
\text { lipid peroxidation inhibitor, } \\
\text { inhibits hallmarkers }\end{array}$ & $\begin{array}{c}{ }^{1} \mathrm{O}_{2}, \\
\mathrm{O}_{2}{ }^{--}, \mathrm{H}_{2} \mathrm{O}_{2}, \mathrm{HO}^{*} \\
\mathrm{NO}, \mathrm{LOOH}, \mathrm{ONOO}^{-}, \mathrm{HOCl}\end{array}$ & {$[6,86,119-123]$} \\
\hline$\beta$-carotene & $\begin{array}{c}{ }^{1} \mathrm{O}_{2} \text { quencher; } \\
\text { radical scavenger; } \\
\text { inhibits } \mathrm{Na}^{+} \mathrm{K}^{+} \text {-ATPase, } \\
\text { stimulates catalase and GS transferase }\end{array}$ & $\begin{array}{c}{ }^{1} \mathrm{O}_{2}, \\
\mathrm{NO}_{2}, \mathrm{ONOOH} \text { and } \mathrm{ONOO}^{-}\end{array}$ & {$[6,124-126]$} \\
\hline canthaxanthin & $\begin{array}{l}\text { ROS and RNS quencher; } \\
\text { chain-breaking AO }\end{array}$ & ${ }^{1} \mathrm{O}_{2}$ & {$[119,121]$} \\
\hline fucoxanthin & $\begin{array}{c}{ }^{1} \mathrm{O}_{2} \text { quencher, } \\
\text { radical scavenger; } \\
\text { inhibits } \mathrm{Na}^{+} \mathrm{K}^{+} \text {-ATPase, stimulates catalase } \\
\text { and glutathione transferase }\end{array}$ & $\begin{array}{c}{ }^{1} \mathrm{O}_{2}, \\
\mathrm{O}_{2}^{\cdot-}, \mathrm{HO}^{*}, \mathrm{ONOO}^{-}, \mathrm{HOCl}, \\
\text { DPPH}{ }^{\bullet}, \text { 12-DS', NB}-\mathrm{L}, \mathrm{AAPH}, \\
\text { ABTS, ABAP, AIBN }\end{array}$ & {$[6,103,124,127-133]$} \\
\hline
\end{tabular}

There is evidence that a diet rich in carotenoids and other bioactive compounds protects from several diseases, including obesity and cancer; oxidative stress is known to be associated with those diseases and malfunctions; hence, carotenoids might inhibit the onset of these diseases due to their AO activity. It is also known that carotenoids exhibit their antioxidative properties by being good scavengers of several chemical radicals and potent quenchers of singlet oxygen (Table 4).

In order to deactivate reactive species and stop oxidative reactions, AO (vitamin C, thiol, fucoxanthin, polyphenols) usually donate electrons, but some can also be proton donors, as happens with fucoxanthin, GSH and $\alpha$-tocopherol [132]. Some of them act as "real" cellular AO (GSH), some others are chainbreaking AO as they can stop oxidative reactions, such as $\alpha$-tocopherol [134].

The unique molecular structures of some carotenoids, which have additional oxygenic functional groups (epoxy, hydroxyl, carbonyl and/or carboxyl), together (or not) with special unique allenic features (Table 1) and several conjugated double bonds, provide them with a strong AO activity, as happens with fucoxanthin [124]. Algal fucoxanthin has already demonstrated to effectively protect from ROS and oxidative-induced damages [135], with the AO activity being higher than that of $\alpha$-tocopherol. Rodrigues and colleagues [6] also found that fucoxanthin was one of the strongest carotenoids scavenging $\mathrm{HOCl}$, only surpassed by astaxanthin. However, in another study, $\beta$-carotene showed to be better a ${ }^{1} \mathrm{O}_{2}$ quencher [124], and halocyanthiaxanthin was the best suppressor of $\mathrm{O}_{2}{ }^{--}$among about twenty carotenoids, despite demonstrating the lowest scavenging properties [136]. In contrast, Pashkow and 
colleagues [137] describe that astaxanthin has the highest AO capacity among several carotenoids, including $\beta$-carotene, zeaxanthin and canthaxanthin, with it being 500 -fold higher than that of vitamin $\mathrm{E}$ as a ${ }^{1} \mathrm{O}_{2}$ quencher [138], and 100 times greater than that of $\alpha$-tocopherol with respect to the protective effects against lipid peroxidation [139]. The AO activity of astaxanthin as a scavenger of various reactive species ( $\mathrm{LOO}^{\circ}, \mathrm{HOCl}$ and $\mathrm{ONOO}^{-}$) was also demonstrated by Rodrigues' group [6]. It was even more potent than $\alpha$-tocopherol. Regarding RNS. However, scarce information is available concerning the capacity of carotenoids to scavenge other radicals, such as $\mathrm{ONOO}^{-}$. However, Rodrigues and co-workers [6] found that $\beta$-carotene was the best $\mathrm{ONOO}^{-}$scavenger among several carotenoids. Also, carotenoids with oxygenic substituents, especially $-\mathrm{OH}$, which can easily donate protons, showed to be better than the hydrophobic carotenes at neutralizing ROS. This dependency on the amounts of oxygen of carotenoids influencing the sensitivity to radicals and their AO was observed by other researchers as well [132,138], with the AO activity usually being inversely correlated with oxygen tension [125].

Despite the lower concentration in carotenoids, mainly astaxanthin, their extraction from palmeloid cells of $H$. pluvialis is easier and their content is more readily available. This is a positive aspect when whole cells are administered to produce antioxidative properties of their carotenoids. Owing to the absence of a hard cell wall, these reddish palmeloid cells are more suitable for human consumption [42]. In certain conditions, when the content in astaxanthin is lower, the fatty acid (FA) content may also play a role in the AO capacity [118] of $H$. pluvialis, perhaps because astaxanthin is present mainly as monoand diesters, especially with oleic acid. According to Cerón et al. [42], the AO power of astaxanthin in vitro against the radical DPPH is 10 times higher than that of $\beta$-carotene, 500 times higher than that of $\alpha$-tocopherol, and diesters are 1.6 times more potent than monoesters and twice as potent as free astaxanthin. In addition to the AO potential, astaxanthin is also an antiglycant [28]. Therefore, this carotenoid is able to protect from glycation of proteins, which may be subsequently oxidized to form glycoxidation products (Table 3). However, protein oxidation products can have a positive oxidative stress response as well. S-nitrosylation of a single cysteine residue and S-sulphenation of cysteine, where sulphydryl group of cysteine is converted to a S-sulphenation product, or addition of a group - $\mathrm{SOH}$ to DJ-1 protein is related to Parkinson's disease; this oxidation product has a positive effect and is neuron protective [7].

Additional protection in cells may come from the beneficial activity of some ROS that can interact with NO to form peroxynitrite (Figure 2), which in turn can react with carotenoids to form nitrocarotenoids that scavenge those radicals. However, few reports exist on this matter [123,129]. Peroxynitrite, a reactive nitrogen species, is responsible for the nitration of tyrosine, as a free aminoacid or as a monomer in proteins, and for the oxidation of LDL, peroxidation of lipids and fragmentation of DNA [140]. Fucoxanthin inhibits nitration of tyrosine by reacting with peroxynitrine and forming $Z$-nitrofucoxanthin [129], thus, proving the capacity to neutralize those radicals. These new products also showed to have anti-tumor and anti-proliferative properties, which are induced/triggered by RNS. This anti-carcinogenic activity of nitrofucoxanthin has even been found to be higher than that of fucoxanthin [129]. Astaxanthin and lutein can also scavenge RNS ONOO` to form 15Z-nitroastaxanthin and 15Z-nitrolutein that, besides maintaining antioxidative activity against oxygen singlet and inhibiting nitration of tyrosine, has shown (as it happens with nitrofucoxanthin [129]) anti-tumorigenic-induced RNS properties higher than those of astaxanthin and lutein [123]. However, astaxanthin demonstrated an $\mathrm{AO}$ activity as a ${ }^{1} \mathrm{O}_{2}$ quencher higher than nitroastaxanthin, and even higher than $\beta$-carotene; lutein 
and nitrolutein have similar ${ }^{1} \mathrm{O}_{2}$ quenching activities, higher than $\beta$-carotene [123]. Astaxanthin showed no cytotoxicity for several kinds of cell-lines, either healthy or tumor cells, when in doses up to $16.75 \mu \mathrm{M}$ [21]. Additionally, no side effects were noticed in the studies reported and reviewed by Fassett and Coombes [13].

In what concerns fucoxanthin, in addition to its high AO activity, this unique carotenoid is also able to modulate certain genes involved in the cell metabolism [141], and these properties seem to be essential for health. However, fucoxanthin metabolites, fucoxanthinol and amarouciaxanthin A, seem to be responsible for the physiological effects in the gastrointestinal tract and liver, respectively, in mice and rats $[107,109,142]$, and the conversion from fucoxanthin into its metabolites has been observed in Caco-2 and HepG2 human cell-lines as well [92,109,110]. Nevertheless, as drugs in general have a shorter retention time in smaller animals [143], the effects of bioactive compounds, such as fucoxanthin and the respective metabolites, cannot be directly compared with the correspondent in humans, where bioavailability is higher due to a slower metabolism. In addition, absorption of fucoxanthin, and perhaps other carotenoids, depends on the food ingested, since its solubility is low in vitamin $\mathrm{E}$ and some vegetable oils, but is rather dissolved in medium-sized triacylglycerols and fish oil [144,145]. Furthermore, as it happens with $\beta$-carotene, the chemically synthesized fucoxanthin might not demonstrate the same functionalities as those from the natural racemic cis-trans mixtures. Regarding safety, fucoxanthin has proven to be a safe product in several studies with different cell-lines and animal models, either administered in one single dose or given over a period of time [146,147], as reported by Peng et al. [103]. Fucoxanthin from marine algae has also proven to be able to regulate lipidemic marker levels in the blood and liver of various (obese) animal models and reduce their white adipose tissue and body weight as well [148-153]. A decrease of body weight, body and liver fat in obese women treated with Xanthigen, some of them with non-alcoholic fatty liver disease (NAFLD), was also observed in a clinical study carried out by Abidov and coworkers [26]. In this study, an increase of energy dissipation, perhaps by thermogenesis, was verified as well in those treated women. Additionally, this xanthophyll carotenoid was also shown to regulate mRNA expression of several cell events and activity of various enzymes [150,153], including lipase activity at the intestinal level [154]. Gammone and D'Orazio [153] and Peng's group [103] focused on the mechanisms of fucoxanthin and its metabolites as powerful agents against obesity. However in most studies, fucoxanthin was not obtained from marine microalgae, but from brown seaweeds. The main mechanism that explains the anti-obesity properties of fucoxanthin and its metabolites seems to be associated to its capacity to stimulate uncoupling proteins (UCPs) $[153,155,156]$. UCP-1 (thermogenin), for example, induces fatty acid oxidation and also inhibits oxidative phosphorylation at the mitochondria level, thus enhancing the burning of excess calories, which are dissipated off (energy expenditure) from the body in the form of heat (thermogenesis) [153].

Moreover, different carotenoids, carotenes or xantophylls with different optical (cis, trans, racemic mixtures) or geometrical $(R / S)$ forms may present different behaviors at the cell membrane level: they can change the membrane permeability and fluidity, as they can cross along the entire membrane (as is the case for astaxanthin and zeaxanthin) or not (as it is likely for $\beta$-carotene and lycopene); this may interfere with their capacity to intercept/react with reactive species/toxins [157]. This could be an explanation for the low ability of $\beta$-carotene to inhibit peroxidation of hydrosoluble peroxyradicals, whereas zeaxanthin and astaxanthin are more able to do so [158]. Additionally, various carotenoids may co-exist in animal and human tissues and, therefore, the effect may be synergistic among those lipophilic carotenoids, such as $\beta$-carotene and lycopene (acting within the hydrophobic bilayer of cell membranes) 
and xanthophyll carotenoids that have polar and non-polar regions, such as astaxanthin and zeaxanthin, which can cross the membrane. This explains why a mixture of carotenoids with different chemical characteristics should be administered to prevent oxidative damage and related diseases. Also, the use of the microalgal biomass of a mixture of different genera, such as Spirulina platensis, H. pluvialis and Dunaliella salina could be suggested.

\subsection{Role of Carotenoids against Reactive Species and Diseases}

Liu and co-workers [86] have untangled the link between oxidative stress-generated cell damages in Parkinson's neurodegenerative disease (PD) and the treatment with the xanthophyll carotenoid astaxanthin. With concentrations as low as $100 \mathrm{nM}$, astaxanthin demonstrated its AO potential to protect mitochondria of dopaminergic cells, inhibiting peroxidation of lipids, which are severely neurotoxic to the cells, therefore preserving loss of dopaminergic neurons and protecting from PD's evolution. The protective effect was dose-dependent and associated to the fact that astaxanthin was preferentially accumulated in mitochondria [86]. Furthermore, the oxidative protection of the brain and the neuroprotective effect of astaxanthin may also be due to the fact that this carotenoid can cross the blood-brain barrier as it has been observed in rats' brain tissue, patented by Tso and Lam in 1996 [159], and in other experimental animals [160]. Astaxanthin also reduced biomarkers 8-OHdG and 4-HNE (Table 3) presented in high levels in cardiac and skeletal muscles of rats, because of the oxidative stress induced by excessive physical exercise [87]. Athletes are particularly affected by oxidative stress due to the high physical efforts, which cause an overproduction of ROS [155]. Thus, an alternative prevention against oxidative stress and the subsequent weakness of the immune system and inflammatory conditions might arise from the intake of carotenoids from marine microalgae, especially astaxanthin and fucoxanthin, two powerful antioxidant carotenoids. In addition, fucoxanthin might be useful, as this marine xanthophyll carotenoid seems to enhance thermogenesis by improving UCPs gene expression and protein activity, decreasing the athlete's body weight, and therefore improving body performance during sports [155]. In addition to astaxanthin from $H$. pluvialis and fucoxanthin from $O$. aurita and P. tricornutum [161,162], other carotenoids that can be obtained from various marine microalgae have already been demonstrated to have a wide range of health benefits. This is the case of violaxanthin from C. ellipsodea [45,163], canthaxanthin from C. vulgaris and C. striolata var. multistriata $[37,44]$.

\section{Why Is There Limited Success of Carotenoids as Anti-Oxidant Agents in Studies/Clinical Trials?}

Some researchers have pointed out a wide range of reasons for the failure of carotenoids as AO in tests and clinical trials $[3,96,125,164]$. The controversial results for the AO properties of carotenoids may possibly be related to an inappropriate choice of the tests for the oxidation products and the biomarkers used, the targeted tissues and the features within the cell. Also the design of the experiment/clinical trial in what concerns the origin and concentration of the right carotenoid, their mechanisms of action and the way of administration, the dose, the duration of the study/therapy, the model/system chosen and the biomarkers selected for the study may have a great influence on the results obtained. Another question has to be asked: are these double-blind placebo-controlled and 
long-term clinical studies/trials with statistically relevant numbers of individuals? In 2011, Fassett and Coombes [13] referred to the non-existence of such clinical trials, at least for CVD treatment/prevention using astaxanthin.

Following this reasoning, the design of such studies/trials should take into account the chemical and structural characteristics of the various carotenoids, naturally produced $v s$. synthetic, their isomeric and geometric structures, their polarity and redox potential and the pattern of responses elicited in different oxygen pressures in order to choose the most sensitive biomarkers. The probability of the various carotenoids to interact and/or be synergistic with other carotenoids and/or other AO during the metabolic reactions in the whole individual should also be considered. The model should be carefully selected since the human absorption, metabolism and bioavailability of carotenoids is different from other animals, and the chosen animal, as a whole system, implies the existence of different needs, enzymes and responses to different carotenoids. Therefore, the effects at the level of the tissues and/or organs are different from those obtained in chemical tests or even in cell lines, where different responses may be triggered. The best animal models seem to be gerbils, ferrets and calves, as they seem to use and metabolize carotenoids in a similar way as humans [96].

It is worth noting though that when the immune system is deficient, leukocytes cannot produce enough superoxide anion or NO and, thus, a pro-oxidant therapy should be required. Therefore, a carotenoid treatment might be useful in order to trigger this pro-oxidant reaction. The doses administered depend most of the time, if not always, on the chosen carotenoid. Fucoxanthin, for example, has already been demonstrated to exert an AO activity by starting some pro-oxidant effects [128]. Responses obtained also depend on the duration of the study/treatment. Furthermore, $\beta$-carotene and other carotenoids can lose their AO properties and act as pro-oxidants when in high concentrations [164-166] and in the presence of oxygen [125]. This may also be related with the carotenoid aggregation. Burton and Ingold [125] decribe that, under high oxygen pressures, some carotenoids can suffer auto-oxidation, which may explain the reduction of their AO effectiveness.

Moreover, the AO/pro-oxidant activity of carotenoids strongly depends on the oxygen $\left(\mathrm{O}_{2}\right)$ pressure, and it has to be considered that, except for the lungs and brain, tissues are normally subjected to low $\mathrm{O}_{2}$ pressures. Furthermore, $\beta$-carotene has demonstrated a better radical scavenging activity under low concentrations of $\mathrm{O}_{2}$ [125], whilst fucoxanthin is better in anoxic conditions, probably due to the oxygen substituents in the chemical structure [132]; however, in another study, fucoxanthin was less active than $\alpha$-tocopherol under high oxygen pressures [167].

Additionally, Sangeetha's group [20,113] demonstrated a higher protection against lipid peroxidation of fucoxanthin when compared to $\beta$-carotene, with respect to the increase of the activity of catalase and glutathione (GS) transferase and modulation of $\mathrm{Na}^{+} \mathrm{K}^{+}$-ATPase (Table 4), thus restraining lipid peroxidative stress. These two carotenoids also showed a singlet oxygen quenching ability by inhibiting oxidation of vitamin D [168].

The biochemistry of carotenoids, the way they act, the mechanisms of their interaction with other AO and with different reactive species, the products that result from these reactions and the dual character, either as AO or as pro-oxidants, of carotenoids were summarized by El-Agamey and colleagues [157]. One reason for the pro-oxidant reactions of carotenoids given by these researchers is the depletion of $\mathrm{AO}$, such as vitamins $\mathrm{C}$ and $\mathrm{E}$, which may result in the formation of carotenoid radicals that can function as oxidizing agents [157]. They also describe that carotenoids may exert their scavenging activity either 
by donating electrons or protons, or by forming adducts with the radicals, depending on their lipophilic or hydrophilic nature. Each type of mechanism may depend on the polarity of the carotenoid as well as on the reactivity of the radicals.

The benefits of carotenoids also depend on their molecular structure: carotene carotenoids ( $\beta$-carotene, lycopene) can only (inter)act within the lipid bilayer of membranes as they do not have polar endings like xanthophyll carotenoids astaxanthin, canthaxanthin and fucoxanthin. This may explain, at least partially, why some carotenoids preserve the membrane integrity better [169] and have protective effects [14], and others may even cause lipid peroxidation and damage in cell membranes $[169,170]$, demonstrating a pro-oxidant potential, when normally administered in high doses [125].

\section{Conclusions/Final Remarks}

Several epidemiologic studies have shown that diets rich in antioxidants reduce the risk of developing several chronic inflammatory diseases, such as Parkinson, diabetes, cancer and CVD. Carotenoids represent the most abundant lipid-soluble phytochemicals, and in vitro and in vivo studies have suggested that they have a large range of biological properties, such as, antioxidant, anti-inflammatory, modulation of gene expression and many others.

Microalgae are a potential novel source of bioactive molecules, including a wide range of different carotenoids. Several carotenoids from marine microalgae have been associated with beneficial health effects. These natural compounds have being used as nutraceuticals and food supplements, although the biomass itself may also be incorporated in novel functional food products. By consuming naturally produced carotenoids from microalgae and the biomass in the diets, along with a healthy way of living, with moderate exercise and a decrease of exposure to oxidative agents, humans' health may improve. This would increase the endogenous antioxidative protection and even prevent some harmful mechanisms and repair damages in the cell and the whole organism. Several pathways involved in the bioactivity of carotenoids have already been disclosed. However, research is still required on the dose-response relations of carotenoids, their metabolites and their effect on the human metabolism.

\section{Acknowledgments}

This work was supported by Fundação para a Ciência e Tecnologia (FCT) of Portuguese Republic Government, in the frame of the project PEst-OE/EQB/LA0016/2013.

\section{Conflicts of Interest}

The authors declare no conflict of interest.

\section{References}

1. Durackova, Z. Some current insights into oxidative stress. Physiol. Res. 2010, 59, 459-469.

2. Reuter, S.; Gupta, S.C.; Chaturvedi, M.M.; Aggarwal, B.B. Oxidative stress, inflammation, and cancer: How are they linked? Free Radic. Biol. Med. 2010, 49, 1603-1616. 
3. Pashkow, F.J. Oxidative stress and inflammation in heart disease: Do antioxidants have a role in treatment and/or prevention? Int. J. Inflam. 2011, 2011, doi:10.4061/2011/514623.

4. Kalam, S.; Gul, M.Z.; Singh, R.; Ankati, S. Free radicals: Implications in etiology of chronic diseases and their amelioration through nutraceuticals. Pharmacologia 2015, 6, 11-20.

5. Kirkham, P. Oxidative stress and macrophage function: A failure to resolve the inflammatory response. Biochem. Soc. Trans. 2007, 35, 284-287.

6. Rodrigues, E.; Marintti, L.R.B.; Mercadante, A.Z. Scavenging capacity of marine carotenoids against reactive oxygen and nitrogen species in a membrane-mimicking system. Mar. Drugs 2012, 10, 1784-1798.

7. Yan, L.-J. Positive oxidative stress in aging and aging-related disease tolerance. Redox Biol. 2014, 2, 165-169.

8. Baynes, J.W. Role of oxidative stress in development of complications in diabetes. Diabetes 1991, 40, 405-412.

9. Helmersson, J.; Arnlöv, J.; Larsson, A.; Basu, S. Low dietary intake of $\beta$-carotene, $\alpha$-tocopherol and ascorbic acid is associated with increased inflammatory and oxidative stress status in a Swedish cohort. Br. J. Nutr. 2009, 101, 1775-1782.

10. Bian, Q.; Gao, S.; Zhou, J.; Qin, J.; Taylor, A.; Johnson, E.J.; Tanq, G.; Sparrow, J.R.; Gierhart, D.; Shanq, F. Lutein and zeaxanthin supplementation reduces photooxidative damage and modulates the expression of inflammation-related genes in retinal pigment epithelial cells. Free Radic. Biol. Med. 2012, 53, 1298-1307.

11. Riccioni, G. Carotenoids and cardiovascular disease. Curr. Atheroscler. Rep. 2009, 11, 434-439.

12. Bhatt, D.L. Anti-inflammatory agents and antioxidants as a possible "third great wave" in cardiovascular secondary prevention. Am. J. Cardiol. 2008, 101, 4-13.

13. Fassett, R.G.; Coombes, J.S. Astaxanthin: A potential therapeutic agent in cardiovascular disease. Mar. Drugs 2011, 9, 447-465.

14. Gross, G.J.; Hazen, S.L.; Lockwood, S.F. Seven day oral supplementation with Cardax (disodium disuccinate astaxanthin) provides significant cardioprotection and reduces oxidative stress in rats. Mol. Cell. Biochem. 2006, 283, 23-30.

15. Speranza, L.; Pesce, M.; Patruno, A.; Fransceschelli, S.; de Lutiis, M.A.; Grilli, A.; Felaco, M. Astaxanthin treatment reduced oxidative induced pro-inflammatory cytokines secretion in U937: SHP-1 as a novel biological target. Mar. Drugs 2012, 10, 890-899.

16. Britton, G. Structure and properties of carotenoids in relation to function. FASEB J. 1995, 9 , 1551-1558.

17. Lavy, A.; Naveh, Y.; Coleman, R.; Mokady, S.; Werman, M.J. Dietary Dunaliella bardawil, a $\beta$-carotene-rich alga, protects against acetic acid-induced small bowel inflammation in rats. Inflamm. Bowel Dis. 2003, 9, 372-379.

18. Chidambara-Murthy, K.N.; Vanitha, A.; Rajesha, J.; Mahadeva-Swamy, M.; Sowmya, P.R.; Ravishankar, G.A. In vivo antioxidant activity of carotenoids from Dunaliella salina-A green microalga. Life Sci. 2005, 76, 1381-1390.

19. Lorenz, R.T.; Cysewski, G.R. Commercial potential for Haematococcus microalgae as a natural source of astaxanthin. Trends Biotechnol. 2000, 18, 160-167. 
20. Sangeetha, R.K.; Bhaskar, N.; Baskaran, V. Fucoxanthin restrains oxidstive stress induced by retinol deficiency through modulation of $\mathrm{Na}^{+} \mathrm{K}^{+}$-ATPase and antioxidant enzyme activities in rats. Eur. J. Nutr. 2008, 47, 432-441.

21. Régnier, P.; Bastias, J.; Rodriguez-Ruiz, V.; Caballero-Casero, N.; Caballo, C.; Sicilia, D.; Fuentes, A.; Maire, M.; Crepin, M.; Letourneur, D.; et al. Astaxanthin from Haematococcus pluvialis prevents oxidative stress on human endothelial cells without toxicity. Mar. Drugs 2015, 13, 2857-2874.

22. Fassett, R.G.; Healy, H.; Driver, R.; Robertson, I.K.; Gesaghy, D.P.; Sharman, J.E.; Coombes, J.S. Astaxanthin $v s$. placebo on arterial stiffness oxidative stress and inflammation in renal transplant patients (Xanthin): A randomized controlled trial. BMC Nephrol. 2008, 9, 17.

23. Guerin, M.; Huntley, M.E.; Olaizola, M. Haematococcus astaxanthin: Applications for human health and nutrition. Trends Biotechnol. 2003, 21, 210-216.

24. Park, J.S.; Chyun, J.H.; Kim, Y.K.; Line, L.L.; Chew, B.P. Astaxanthin decreased oxidative stress and inflammation and enhanced immune response in humans. Nutr. Metab. 2010, 5, 7-18.

25. Bobrov, Z.; Tracton, I.; Taunton, K.; Mathews, M. Effectiveness of whole dried Dunaliella salina marine microalgae in the chelating and detoxification of toxic minerals and heavy metals. Available online: http://www.interclinical.com.au/publications/archived\%20publications/ DetoxPaper100308.pdf (assessed on 5 August 2014).

26. Abidov, M.; Ramazanov, Z.; Seifulla, R.; Grachev, S. The effects of Xanthigen in the weight management of obese premenopausal women with non-alcoholic live disease and normal liver fat. Diabetes Obes. Metable. 2010, 12, 72-81.

27. Han, D.; Li, Y.; Hu, Q. Astaxanthin in microalgae: Pathways, functions and biotechnological implications. Algae 2013, 28, 131-147.

28. Sun, Z.; Liu, J.; Bi, Y.-H.; Zhou, Z.-G. Microalgae as the production platform for carotenoids. In Recent Advances in Microalgal Biotechnology; Liu, J., Sun, Z., Gerken, H., Eds.; Omics Group eBooks: Foster City, CA, USA, 2014; pp. 1-17.

29. Takaichi, S. Carotenoids in algae: Distribution, biosynthesis and function. Mar. Drugs 2011, 9 , 1101-1118.

30. Dembitsky, V.M.; Maoka, T. Allenic and cumulenic lipids. Prog. Lipid Res. 2007, 46, 328-375.

31. El-Baz, F.K.; Abdoul-Enein, A.M.; El-Baroty, G.-S.; Youssef, A.M.; El-Baky, H.H.A. Accumulation of antioxidant vitamins in Dunaliella salina. J. Biol. Sci. 2002, 2, 220-223.

32. Bar, E.; Rise, M.; Vishkautsan, M.; Arad, S. Pigment and structural changes in Chlorella zofingiensis upon light and nitrogen stress. J. Plant Physiol. 1995, 146, 527-534.

33. Patel, A.; Mishr, S.; Pawar, R.; Ghosh, P.K. Purification and characterization of C-phycocyanin from cyanobacterial species of marine and freshwater habitat. Protein Express. Purif. 2005, 40, 248-255.

34. Miranda, M.S.; Cintra, R.G.; Barros, S.B.; Mancini-Filho, J. Antioxidant activity of the microalga Spirulina maxima. Braz. J. Med. Biol. Res. 1998, 31, 1075-1079.

35. El-Baky, H.H.A.; El-Baz, F.K.; El-Baroty, G.-S. Spirulina species as a source of carotenoids and $\alpha$-tocopherol and its anticarcinoma factors. Biotechnology 2003, 2, 222-240. 
36. Jaime, L.; Mendiola, J.A.; Herrero, M.; Soler-Rivas, C.; Santoyo, S.; Señorans, F.J.; Cifuentes, A.; Ibáñez, E. Separation and characterization of antioxidants from Spirulina platensis microalga combining pressurized liquid extraction, TLC, and HPLC-DAD. J. Sep. Sci. 2005, 28, 2111-2119.

37. Abe, K.; Hattori, H.; Hirano, M. Accumulation and antioxidant activity of secondary carotenoids in the aerial microalga Coelastrella striolata var. multistriata. Food Chem. 2007, 100, 656-661.

38. Hata, N.; Ogbonna, J.C.; Hasegawa, Y.; Taroda, H.; Tanaka, H. Production of astaxanthin by Haematococcus pluvialis in a sequential heterotrophic-photoautotrophic culture. J. Appl. Phycol. 2001, 13, 395-402.

39. Kang, C.D.; Lee, J.S.; Park, T.H.; Sim, S.J. Comparison of heterotrophic and photoautotrophic induction on astaxanthin production by Haematococcus pluvialis. Appl. Microbiol. Biotechnol. 2005, 68, 237-241.

40. Steinbrenner, J.; Linden, H. Regulation of two carotenoid biosynthesis genes coding for phytoene synthase and carotenoid hydrolase during stress-induced astaxanthin formation in the green alga Haematococcus pluvialis. Plant Physiol. 2001, 125, 810-817.

41. Nobre, B.; Marcelo, F.; Passos, R.; Beirão, L.; Palavra, A.; Gouveia, L.; Mendes, R. Supercritical carbon dioxide extraction of astaxanthin and other carotenoids from the microalga Haematococcus pluvialis. Eur. Food Res. Technol. 2006, 223, 787-790.

42. Cerón, M.C.; García-Malea, M.C.; Rivas, J.; Acien, F.G.; Fernandez, J.M.; del Rio, E.; Guerrero, M.G.; Molina, E. Antioxidant activity of Haematococcus pluvialis cells grown in continuous culture as a function of their carotenoid and fatty acid content. Appl. Microbiol. Biotechnol. 2007, 74, 1112-1119.

43. Wu, Z.; Wu, S.; Shi, X. Supercritical fluid extraction and determination of lutein in heterotrophically cultivated Chlorella pyrenoidosa. J. Food Proc. Eng. 2007, 30, 174-185.

44. Mendes, R.L.; Fernandes, H.L.; Coelho, J.P.; Reis, E.C.; Cabral, J.M.S.; Novais, J.M. Palavra, A.F. Supercritical $\mathrm{CO}_{2}$ extraction of carotenoids and other lipids from Chlorella vulgaris. Food Chem. 1995, 53, 99-103.

45. Cha, K.H.; Koo, S.Y.; Lee, D.-U. Antiproliferative effects of carotenoids extracted from Chlorella ellipsoidea and Chlorella vulgaris on human colon cancer cells. J. Agric. Food Chem. 2008, 56, 10521-10526.

46. Kim, S.M.; Jung. Y.-J.; Kwon, O.-N.; Cha, K.H.; Um, B.-H.; Chung, D.; Pan, C.-H. A potential commercial source of fucoxanthin extracted from the microalga Phaeodactylum tricornutum. Appl. Biochem. Biotechnol. 2012, 166, 1843-1855.

47. Ragni, M.; d'Alcalá, M.R. Circadian variability in the photobiology of Phaeodactylum tricornutum: Pigment content. J. Plankton Res. 2007, 29, 141-156.

48. Dambek, M.; Eilers, U.; Breitenbach, J.; Steiger, S.; Büchel, C.; Sandmann, G. Biosynthesis of fucoxanthin and diadinoxanthin and function of initial pathway genes in Phaeodactylum tricornutum. J. Exp. Bot. 2012, 63, 5607-5612.

49. Kim, S.M.; Kang, S.-W.; Kwon, O.N.; Chung, D.; Pan, C.-H. Fucoxanthin as a major carotenoid in Isochrysis aff. galbana: Characterization of extraction for commercial application. J. Korean Soc. Appl. Biol. Chem. 2012, 55, 477-483.

50. Rijstenbil, J.W. Effects of UVB radiation and salt stress on growth, pigments and oxidative defence of the marine diatom Cylindrotheca closterium. Mar. Ecol. Prog. Ser. 2003, 254, 37-48. 
51. Xia, S.; Wang, K.; Wan, L.; Li, A.; Hu, Q.; Zhang, C. Production, characterization, and antioxidant activity of fucoxanthin from the marine diatom Odontella aurita. Mar. Drugs 2013, 11, 2667-2681.

52. Schubert, N.; García-Mendoza, E.; Pacheco-Ruiz, I. Carotenoid composition of marine red algae. J. Phycol. 2006, 42, 1208-1216.

53. Tonegawa, I.; Okada, S.; Murakami, M.; Yamagushi, K. Pigment composition of the green microalga Botryococcus braunii Kawagushi-1. Fish. Sci. 1998, 64, 305-308.

54. Lichtenthaler, T.K. The 1-deoxy-D-xylulose-5-phosphate pathway of isoprenoid biosynthesis in plants. Annu. Rev. Plant Physiol. Plant Mol. Biol. 1999, 50, 47-65.

55. Disch, A.; Schwender, J.; Müller, C.; Lichtenthaler, H.K.; Rohmer, M. Distribution of the mevalonate and glyceraldehyde phosphate/pyruvate pathways for isoprenoid biosynthesis in unicellular algae and the cyanobacterium Synechocystis PCC 6714. Biochem. J. 1998, 333, 381-388.

56. Miziorko, H.M. Enzymes of the mevalonate pathway of isoprenoid biosynthesis. Arch. Biochem. Biophys. 2011, 505, 131-143.

57. Cunningham, F.X.; Gantt, E. Genes and enzymes of carotenoid biosynthesis in plants. Annu. Rev. Plant Physiol. Plant Mol. Biol. 1998, 49, 557-583.

58. Grünewald, K.; Eckert, M.; Hirschberg, J.; Hagen, C. Phytoene desaturase is localized exclusively in the chloroplast and up-regulated at the mRNA level during accumulation of secondary carotenoids in Haematococcus pluvialis (Volvocales, Chlorophyceae). Plant Physiol. 2000, 122, 1261-1268.

59. Steinbrenner, J.; Linden, H. Light induction of carotenoid biosynthesis genes in the green alga Haematococcus pluvialis: Regulation of photosynthetic redox control. Plant Mol. Biol. 2003, 52, 343-356.

60. Cunningham, F.X.; Pogson, B.; Sun, Z.; McDonald, K.A.; Della Penna, D.; Gantt, E. Functional analysis of the beta and epsilon lycopene cyclase enzymes of Arabidopsis reveals a mechanism for control of cyclic carotenoid formation. Plant Cell 1996, 8, 1613-1626.

61. Bertrand, M. Carotenoid biosynthesis in diatoms. Photosynth. Res. 2010, 106, 89-102.

62. Ayala, A.; Muñoz, M.F.; Argüelles, S. Lipid peroxidation: Production, metabolism, and signaling mechanisms of malondialdehyde and 4-hydroxy-2-nonenal. Oxid. Med. Cell. Longev. 2014, 2014, doi:10.115/2014/360438.

63. Halliwell, B. Reactive species and antioxidants. Redox biology is a fundamental theme of aerobic life. Plant Physiol. 2006, 141, 312-322.

64. Miyamoto, S.; Martinez, G.R.; Rettori, D.; Augusto, O.; Medeiros, M.H.G.; Di Mascio, P. linoleic hydroperoxide reacts with hypochlorous acid, generating peroxyl radical intermediates and singlet molecular oxygen. Proc. Natl. Acad. Sci. USA 2006, 103, 293-298.

65. Miyamoto, S.; Ronsein, G.E.; Prado, F.M.; Uemi, M.; Corrêa, T.C.; Toma, I.N.; Bertolucci, A.; Oliveira, M.C.B.; Motta, F.D.; Medeiros, M.H.G.; et al. Biological hydroperoxides and singlet molecular oxygen generation. IUBMB Life 2007, 59, 322-331.

66. Halliwell, B. Free radicals, antioxidants, and human disease: Curiosity, cause or consequence? Lancet 1994, 344, 721-724. 
67. Wink, D.A.; Kasprak, K.S.; Maragos, C.M.; Elespuru, R.K.; Misra, M.; Dunams, T.M.; Cebula, T.A.; Koch, W.H.; Andrews, A.W.; Allen, J.S.; et al. DNA deaminating activity and genotoxicity of nitric oxide and its progenitors. Science 1991, 254, 1001-1003.

68. Gutowski, M.; Kowalczyk, S. A study of free radical chemistry: Their role and pathophysiological significance. Acta Biochem. Pol. 2013, 60, 1-16.

69. Kanner, J.; German, J.B.; Kinsella, J.E. Initiation of lipid peroxidation in biological systems. Crit. Rev. Food Sci. Nutr. 1987, 25, 317-364.

70. Negre-Salvayre, A.; Coatrieux, C.; Ingueneau, C.; Salvayre, R. Advanced lipid peroxidation end products in oxidative damage to proteins. Potential role in diseases and therapeutic prospects for the inhibitors. Br. J. Pharmacol. 2008, 153, 6-20.

71. Halliwell, B.; Gutteridge, J.M.C. Oxygen toxicity, oxygen radicals, transition metals and disease. Biochem. J. 1984, 219, 1-14.

72. Mezzetti, A.; Guglielmi, M.D.; Pierdomenico, S.D.; Costantini, F.; Cipollone, F.; De Cesare, D.; Bucciarelli, T.; Ucchino, S.; Chiarelli, F.; Cuccurullo, F.; et al. Increased systemic oxidative stress after elective endarterectomy. Arterioscler. Thromb. Vasc. Biol. 1999, 19, 2659-2665.

73. Nishigaki, I.; Hagihara, M.; Tsunekawa, H.; Maseki, M.; Yagi, K. Lipid peroxide levels of serum lipoprotein fractions of diabetic patients. Biochem. Med. 1981, 25, 373-378.

74. Klaunig, J.E.; Kamendulis, L.M.; Hocevar, B.A. Oxidative stress and oxidative damage in carcinogenesis. Toxicol. Pathol. 2010, 38, 96-109.

75. Klaunig, J.E.; Kamendulis, L.M. The role of oxidative stress in carcinogenesis. Annu. Rev. Pharmacol. Toxicol. 2004, 44, 239-267.

76. Mezzetti, A.; Cipollone, F.; Cuccurullo, F. Oxidative stress and cardiovascular complications in diabetes: Isoprostanes as new markers on an old paradigm. Cardiovasc. Res. 2000, 47, 475-488.

77. Praticò, D.; FitzGerald, G.A. Generation of 8-epi prostaglandin $F_{2 \alpha}$ by human monocytes: Discriminate production by reactive oxygen species and prostaglandin endoperoxide synthase- 2 . J. Biol. Chem. 1996, 271, 8919-8924.

78. Wolff, S.P.; Dean, R.T. Glucose autoxidation and protein modification: Their potential role of autoxidative glycosylation in diabetes. Biochem. J. 1987, 245, 243-250.

79. Nourooz-Zadeh, J.; Tajaddini-Sarmadi, J.; McCarthy, S.; Betteridge, D.J.; Wolff, S.P. Elevated levels of authentic plasma hydroperoxides in NIDDM. Diabetes 1995, 44, 1054-1058.

80. Poljak, K.B.; Milisav, I. Aging, oxidative stress and antioxidants. InTech 2013, 14, 331-353.

81. Giera, M.; Lingeman, H.; Niessen, W.M.A. Recent advancements in the LC- and GC-based analysis of malondialdehyde (MDA): A brief overview. Chromatographia 2012, 75, 433-440.

82. Argüelles, S.; García, S.; Maldonado, M.; Machado, A.; Ayala, A. Do the serum oxidative stress biomarkers provide a reasonable index of the general oxidative stress status? Biochim. Biophys. Acta 2004, 1674, 254-259.

83. McCance, D.R.; Dyer, D.G.; Dunn, J.A.; Bailie, K.E.; Thorpe, S.R.; Baynes, J.W.; Lyons, T.J. Maillard reaction products and their relation to the complications of diabetes. J. Clin. Invest. 1993, 91, 2470-2478.

84. Wang, S.F., Yen, J.C., Yin, P.H., Chi, C.W., Lee, H.C. Involvement of oxidative stress-activated JNK signalling in the methamphetamine-induced cell death of human SH-SY5Y cells. Toxicology 2008, 246, 234-241. 
85. Hasegawa, T.; Matsuzaki, M.; Takeda, A.; Kikuchi, A.; Furukawa, K.; Shibahara, S.; Itoyama, Y. Increased dopamine and its metabolites in SH-SY5Y neuroblastoma cells that express tyrosinase. J. Neurochem. 2003, 87, 470-475.

86. Liu, X.; Shibata, T.; Hisaka, S.; Osawa, T. Astaxanthin inhibits reactive oxygen species mediated cellular toxicity in dopaminergic SH-SY5Y cells via mitochondria-targeted protective mechanism. Brain Res. 2009, 1254, 18-27.

87. Aoi, W.; Naito, Y.; Sakama, K.; Kuchide, M.; Tokuda, H.; Maoka, T.; Toyokumi, S.; Oka, S.; Yasuhara, M.; Yoshikawa, T. Astaxanthin limits exercise-induced skeletal and cardiac muscle damage in mice. Antioxid. Redox Signal. 2003, 5, 139-144.

88. Nakao, R.; Nelson, O.L.; Park, J.S.; Mathison, B.D.; Thompson, P.A.; Chew, B.P. Effect of astaxanthin supplementation on inflammation and cardiac function in BALB/c mice. Anticancer Res. 2010, 30, 2721-2725.

89. Praticò, D.; Iuliano, L.; Spagnoli, L.; Mauriello, A.; Lawson, J.A.; Rokach, J.; Maclouf J.; Violi, F.; FitzGerald, G.A. Localization of distinct F2 isoprostanes in human atherosclerotic lesions. J. Clin. Invest. 1997, 100, 2028-2034.

90. Praticò, D.; Barry, O.P.; Lawson, J.A.; Adiyaman, M.; Hwang, S.W.; Khanapure, S.P.; Iuliano, L.; Rokach, J.; FitzGerald, G.A. IPF2 $\alpha$-I: An index of lipid peroxidation in humans. Proc. Natl. Acad. Sci. USA 1998, 95, 3449-3454.

91. Guiwotta, C.; Morrow, J.D.; Roberts, L.J.I.I.; Kuhn, H. Prostaglandin F2-like compounds, F2-isoprostanes, are present in increased amounts in human atherosclerotic lesions. Arterioscler. Thromb. Vasc. Biol. 1997, 17, 3236-3241.

92. Sugawara, T.; Kushiro, M.; Zhang, H.; Nara. E.; Ono, H.; Nagao, A. Lysophosphatidylcholine enhances carotenoid uptake from mixed micelles by Caco-2 human intestinal cells. J. Nutr. 2001, 131, 2921-2927.

93. Olson, J.A. Absorption, transport, and metabolism of carotenoids in humans. Pure Appl. Chem. 1994, 66, 1011-1106.

94. Parker, R.S. Absorption, metabolism, and of transport carotenoids. FASEB J. 1996, 10, 542-551.

95. Furr, H.C.; Clark, R.M. Intestinal absorption and tissue distribution of carotenoids. J. Nutr. Biochem. 1997, 8, 364-377.

96. Elliot, R. Mechanisms of genomic and non-genomic actions of carotenoids. Biochim. Biophys. Acta 2005, 1740, 147-154.

97. Paetau, I.; Chen, H.; Goh, N.M.-Y.; White, W.S. Interactions of the postprandial appearance of $\beta$-carotene and canthaxanthin in plasma triacylglycerol-rich lipoproteins in humans. Am. J. Clin. Nutr. 1997, 66, 1133-1143.

98. Stahl, W.; Schwarz, W.; van Laar, J.; Sies, H. All-trans- $\beta$-carotene preferentially accumulates in human chylomicron and very low density lipoproteins compared with 9-cis geometrical isomer. J. Nutr. 1995, 125, 2128-2133.

99. Krinsky, N.I.; Cornwell, D.G.; Oncley, J.L. The transport of vitamin A and carotenoids in human plasma. Arch. Biochem. Biophys. 1958, 73, 233-246.

100. Goulinet, S.; Chapman, M.J. Plasma LDL and HDL subspecies are heterogeneous in particle content of tocopherols and oxygenated and hydrocarbon carotenoids. Arterioscl. Thromb. Vasc. Biol. 1997, 17, 786-796. 
101. Østerlie, M.; Bjerkeng, B.; Liaan-Jensen, S. Plasma appearance and distribution of astaxanthin $E / Z$ and $R / S$ isomers in plasma lipoproteins of men after single dose administration of astaxanthin. J. Nutr. Biochem. 2000, 11, 482-490.

102. Gärtner, C.; Stahl, W.; Sies, H. Preferential increase in chylomicron levels of xanthophylls lutein and zeaxanthin compared to $\beta$-carotene in the human. Int. J. Vitamin Nutr. Res. 1996, 66, $119-125$.

103. Peng, J.; Yuan, J.-P.; Wu, C.-F.; Wang, J.-H. Fucoxanthin, a marine carotenoid present in brown seaweeds and diatoms: Metabolism and bioactivities relevant to human health. Mar. Drugs 2011, 9, 1806-1828.

104. Odeberg, J.M.; Lignell, A.; Petterson, A.; Hoglung, P. Oral bioavailability of the antioxidant astaxanthin in humans is enhanced by incorporation of lipid based formulations. Eur. J. Pharm. Sci. 2003, 19, 299-304.

105. Manabe, E.; Handa, O.; Naito, Y.; Mizushima, K.; Akagiri, S.; Adachi, S.; Takagi, T.; Kokura, S.; Maoka, T.; Yoshikawa, T. Astaxanthin protects mesangial cells from hyperglycemia-induced oxidative signaling. J. Cell. Biochem. 2008, 103, 1925-1937.

106. Yonekura, L.; Kobayashi, M.; Terasaki, M.; Nagao, A. Keto-carotenoids are the major metabolites of dietary lutein and fucoxanthin in mouse tissues. J. Nutr. 2010, 140, 1824-1831.

107. Hashimoto, T.; Ozaki, Y.; Taminato, M.; Das, S.K.; Mizuno, M.; Yoshimura, K.; Maoka, T.; Kanazawa, K. The distribution and accumulation of fucoxanthin and its metabolites after oral administration in mice. Br. J. Nutr. 2009, 102, 242-248.

108. Strand, A.; Herstad, O.; Liaaen-Jensen, S. Fucoxanthin metabolites in egg yolks of laying hens. Comp. Biochem. Phys. A Mol. Integr. Physiol. 1998, 119, 963-974.

109. Sugawara, T.; Baskaran, V.; Tsuzuki, W.; Nagao, A. Brown algae fucoxanthin is hydrolyzed to fucoxanthinol during absorption by Caco-2 human intestinal cells and mice. J. Nutr. 2002, 132, 946-951.

110. Asai, A.; Sugawara, T.; Ono, H.; Nagao, A. Biotransformation of fucoxanthinol into amarouciaxanthin A in mice and Hep G2 cells: Formation and cytotoxicity of fucoxanthin metabolites. Drug Metab. Dispos. 2004, 32, 205-211.

111. Nishino, H.; Tsushima, M.; Matsuno, T.; Tanaka, Y.; Okuzumi, J.; Murakoshi, M.; Satomi, Y.; Takatasu, Y.; Tokuda, H.; Nishino, A. Anti-neoplastic effect of halocynthiaxanthin, a metabolite of fucoxanthin. Anticancer Drugs 1992, 3, 493-497.

112. Das, S.K.; Ren, R.D.; Hashimoto, T.; Kanazawa, K. Fucoxanthin induces apoptosis in osteoclast-like cells differentiated from RAW264.7 cells. J. Agric. Food Chem. 2010, 58, 6090-6095.

113. Sangeetha, R.K.; Bhaskar, N.; Baskaran, V. Comparative effects of $\beta$-carotene and fucoxanthin on retinol deficiency induced oxidative stress in rats. Mol. Cell. Biochem. 2009, 331, 59-67.

114. Rao, A.R.; Baskaran, V.; Sarada, R.; Ravishankar, G.A. In vivo bioavailability and antioxidant activity of carotenoids from microalgal biomass-A repeated dose study. Food Res. Int. 2013, 54, 711-717.

115. Ben-Amotz, A.; Levy, Y. Bioavailability of natural isomers mixture compared with synthetic all-trans $\beta$-carotene in human serum. Am. J. Clin. Nutr. 1996, 63, 729-734. 
116. Okada, Y.; Ishikura, M.; Maoka, T. Bioavailability of astaxanthin in Haematococcus algal extract: The effects of timing of diet and smoking habits. Biosci. Biotechnol. Biochem. 2009, 73, 1928-1932.

117. Coral-Hinostroza, G.; Ytrestoyl, T.; Ruyter, B.; Bjerkeng, B. Plasma appearance of unesterified astaxanthin geometrical $E / Z$ and optical $R / S$ isomers in men given single doses of a mixture of optical 3 and $3^{\prime} R / S$ isomers of astaxanthin fatty acids diesters. Comp. Biochem. Physiol. C Toxicol. Pharmacol. 2004, 139, 99-110.

118. Raposo, M.F.J.; Morais, A.M.M.B. Microalgae for the prevention of cardiovascular disease and stroke. Life Sci. 2015, 125, 32-41.

119. Miki, W. Biological functions and activities of animal carotenoids. Pure Appl. Chem. 1991, 63, 141-146.

120. Palozza, P., Krinsky, N.I. Astaxanthin and canthaxanthin are potent antioxidants in a membrane model. Arch. Biochem. Biophys. 1992, 297, 291-295.

121. Krinsky, N.I. Antioxidant functions of carotenoids. Free Radic. Biol. Med. 1989, 7, 617-635.

122. Khan, S.K.; Malinski, T.; Mason, R.P.; Kubant, R.; Jacob, R.F.; Fujioka, K.; Denstadet, S.J.; King, T.J.; Jackson, H.L.; Hieber, A.D.; et al. Novel astaxanthin prodrug (CDX-085) attenuates thrombosis in a mouse model. Thromb. Res. 2010, 126, 299-305.

123. Maoka, T.; Tokuda, H.; Suzuki, N.; Kato, H.; Etoh, H. Anti-oxidative, anti-tumor-promoting, anti-carcinogenesis activities of nitroastaxanthin and nitrolutein, the reaction products of astaxanthin and lutein with peroxynitrite. Mar. Drugs 2012, 10, 1391-1399.

124. Sachindra, N.M.; Sato, E.; Maeda, H.; Hosokawa, M.; Niwano, Y.; Kohno, M.; Miyashita, K. Radical scavenging and singlet oxygen quenching activity of marine carotenoid fucoxanthin and its metabolites. J. Agric. Food Chem. 2007, 55, 8516-8522.

125. Burton, G.W.; Ingold, K.U. $\beta$-Carotene: An unusual type of lipid antioxidant. Science 1984, 224 , 569-573.

126. Kikugawa, K.; Hiramoto, K.; Tomiyama, S.; Assano, Y. $\beta$-Carotene effectively scavenges toxic nitrogen dioxide and peroxynitrous acid. FEBS Lett. 1997, 404, 175-178.

127. Zaragozá, M.C.; López, D.; Sáiz, M.P.; Poquet, M.; Pérez, J.; Puig-Parellada, P.; Mármol, F.; Simonetti, P.; Gardana, C.; Lerat, Y.; et al. Toxicity and antioxidant activity in vitro and in vivo of two Fucus. vesiculosus extracts. J. Agric. Food Chem. 2008, 56, 7773-7780.

128. Liu, C.L.; Chin, Y.T.; Hu, M.-L. Fucoxanthin enhances HO-1 and NQO1 expression in murine hepatic BNL CL.2 cells through activation of the Nrf2/ARE system partially by its pro-oxidant activity. J. Agric. Food Chem. 2011, 59, 11344-11351.

129. Tsuboi, M.; Etoh, H.; Kato, K.; Nakatugawa, H.; Kato, H.; Maejima, Y.; Matsumoto, G.; Mori, H.; Hosokawa, M.; Miyashita, K.; et al. Nitrocapsanthin and nitrofucoxanthin, respective products of capsanthin and fucoxanthin reaction with peroxynitrite. J. Agric. Food Chem. 2011, 59, 1057210578.

130. Yan, X.; Chuda, Y.; Suzuki, M.; Nagata, T. Fucoxanthin as the major antioxidant in Hizikia fusiformis, a common edible seaweed. Biosci. Biotechnol. Biochem. 1999, 63, 605-607.

131. Higgins, M. Risk factors associated with chronic obstructive lung disease. Ann. N. Y. Acad. Sci. 1991, 624, 7-17. 
132. Nomura, T.; Kikuchi, M.; Kubodera, A.; Kawakami, Y. Proton-donative antioxidant activity of fucoxanthin with 1,1-diphenyl-2-picrylhydrazyl (DPPH). Biochem. Mol. Biol. Int. 1997, 42, 361-370.

133. Kikuchi, M.; Hirano, A.; Kunito, S.; Kawakami, Y. Fucoxanthin, an antioxidative substance from marine diatom Phaeodactylum tricornutum. J. Mar. Biotechnol. 1995, 3, 132-135.

134. Paravicini, T.M.; Touyz, R.M. NADPH oxidases, reactive oxygen species, and hypertension: Clinical inplications and therapeutic possibilities. Diabetes Care 2008, 31, 170-180.

135. Heo, S.J.; Ko, S.C.; Kang, S.M.; Kang, H.S.; Kim, J.P.; Kim, S.H.; Lee, K.W.; Cho, M.G.; Jeon, Y.J. Cytoprotective effect of fucoxanthin isolated from brown algae Sargassum siliquastrum against $\mathrm{H}_{2} \mathrm{O}_{2}$-induced cell damage. Eur. Food Res. Technol. 2008, 228, 145-151.

136. Murakami, A.; Nakashima, M.; Koshiba, T.; Maoka, T.; Nishino, H.; Yano, M.; Sumida, T.; Kim, O.K.; Koshimizu, K.; Ohigashi, H. Modifying effects of carotenoids on superoxide and nitric oxide generation from stimulated leucocytes. Cancer Lett. 2000, 149, 115-123.

137. Pashkow, F.J.; Watumull, D.G.; Campbell, C.L. Astaxanthin: A novel potential treatment for oxidative stress and inflammation in cardiovascular disease. Am. J. Cardiol. 2008, 101, 58-68.

138. Shimidzu, N.; Goto, M.; Miki, W. Carotenoids as singlet oxygen quenchers in marine organisms. Fish. Sci. 1996, 62, 134-137.

139. Kurashige, M.; Okimasu, E.; Inoue, M.; Utsumi, K. Inhibition of oxidative injury of biological membranes by astaxanthin. Physiol. Chem. Phys. Med. NMR 1990, 22, 27-38.

140. Scheidegger, R.; Pande, A.K.; Bounds, P.L.; Koppenol, W.H. The reaction of peroxynitrite with zeaxanthin. Nitric Oxide 1998, 2, 8-16.

141. Miyashita, K. Function of marine carotenoids. Forum Nutr. 2009, 61, 136-146.

142. Asai, A.; Yonekura, L.; Nagao, A. Low bioavailability of dietary epoxyxanthophylls in humans. Br. J. Nutr. 2008, 100, 273-277.

143. Mordenti, J. Man versus beast: Pharmacokinetic scalling in mammals. J. Pharm. Sci. 1986, 75, 1028-1040.

144. Maeda, H.; Hosokawa, M.; Sashima, T.; Funayama, K.; Miyashita, K. Dietary combination of fucoxanthin and fish oil attenuates the weight gain of white adipose tissue and decreases blood glucose in obese/diabetic KK-A ${ }^{\mathrm{y}}$ mice. J. Agric. Food Chem. 2007, 55, 7701-7706.

145. Maeda, H.; Hosokawa, M.; Sashima, T.; Miyashita, K. Effect of medium-chain triacylglycerols on anti-obesity effect of fucoxanthin. J. Oleo Sci. 2007, 56, 615-621.

146. Beppu, F.; Niwano, Y.; Tsukui, T.; Hosokawa, M.; Miyashita, K. Single and repeated oral dose toxicity study of fucoxanthin (FX), a marine carotenoid, in mice. J. Toxicol. Sci. 2009, 34, 501-510.

147. Iio, K.; Okada, Y.; Ishikura, M. Single and 13-week oral toxicity study of fucoxanthin oil from microalgae in rats. Shokuhin Eiseigaku Zasshi 2011, 52, 183-189.

148. Maeda, H.; Hosokawa, M.; Sashima, T.; Funayama, K.; Miyashita, K. Fucoxanthin from edible seaweed, Undaria pinnatifida, shows antiobesity effect through UCP1 expression in white adipose tissues. Biochem. Biophys. Res. Commun. 2005, 332, 392-397.

149. Maeda, H.; Hosokawa, M.; Sashima, T.; Murakami-Funayama, K.; Miyashita, K. Anti-obesity and anti-diabetic effects of fucoxanthin on diet-induced obesity conditions in a murine model. Mol. Med. Rep. 2009, 2, 897-902. 
150. Woo, M.N.; Jeon, S.M.; Kim, H.J.; Lee, M.K.; Shin, S.K.; Shin, Y.C.; Park, Y.B.; Choi, M.S. Fucoxanthin supplementation improves plasma and hepatic lipid metabolism and blood glucose concentration in high-fat fed C57BL/6N mice. Chem. Biol. Interact. 2010, 186, 316-322.

151. Jeon, S.M.; Kim, H.J.; Woo, M.N.; Lee, M.K.; Shin, Y.C.; Park, Y.B.; Choi, M.S. Fucoxanthin-rich seaweed extract suppresses body weight gain and improves lipid metabolism in high-fat-fed C57BL/6J mice. Biotechnol. J. 2010, 5, 961-969.

152. Hosokawa, M.; Miyashita, T.; Nishikawa, S.; Emi, S.; Tsukui, T.; Beppu, F.; Okada, T.; Miyashita, K. Fucoxanthin regulates adipocytokine mRNA expression in white adipose tissue of diabetic/obese KK-A ${ }^{\mathrm{y}}$ mice. Arch. Biochem. Biophys. 2010, 504, 17-25.

153. Gammone, M.A; D’Orazio, N. Anti-obesity activity of the marine carotenoid fucoxanthin. Mar. Drugs 2015, 13, 2196-2214.

154. Matsumoto, M.; Hosokawa, M.; Matsukawa, N.; Hagio, M.; Shinoki, A.; Nishimukai, M.; Miyashita, K.; Yajima, T.; Hara, H. Suppressive effects of the marine carotenoids, fucoxanthin and fucoxanthinol on triglyceride absorption in lymph duct-cannulated rats. Eur. J. Nutr. 2010, 49, $243-249$.

155. Gammone, M.A; Gemello, E.; Riccioni, G.; D’Orazio, N. Marine bioactives and potential application in sports. Mar. Drugs 2014, 12, 2357-2382.

156. D’Orazio, N.; Gammone, M.A.; Gemello, E., de Girolamo, M.; Cusenza, S.; Riccioni, G. Marine bioactives: Pharmacological properties and potential applications against inflammatory diseases. Mar. Drugs 2012, 10, 812-833.

157. El-Agamey, A.; Lowe, G.M.; McGarvey, D.J.; Mortensen, A.; Phillip, D.M.; Truscott, T.G.; Young, A.J. Carotenoid radical chemistry and antioxidant/pro-oxidant properties. Arch. Biochem. Biophys. 2004, 430, 37-48.

158. Woodall, A.A.; Britton, G.; Jackson M.J. Carotenoids and protection of phospholipids in solution or in liposomes against oxidation by peroxyl radicals: Relationship between carotenoid structure and protective ability. Biochim. Biophys. Acta 1997, 1336, 575-586.

159. Tso, M.O.M.; Lam, T.T. Method of Retarding and Ameliorating Central Nervous System and Eye Damage. U.S. Patent 5527533, 18 June 1996.

160. Hussein, G.; Nakamura, M.; Zhao, Q.; Iguchi, T.; Goto, H.; Sankawa, U.; Watanabe, H. Antihypertensive and neuroprotective effects of astaxanthin experimental animals. Biol. Pharm. Bull. 2005, 28, 47-52.

161. Moreau, D.; Tomasoni, C.; Jacquot, C.; Kaas, R.; Le Guedes, R.; Cadoret, J.P.; Müller-Feuga, A.; Kontiza, I.; Vagias, C.; Roussis, V.; et al. Cultivated microalgae and the carotenoid fucoxanthin from Odontella aurita as potent anti-proliferative agents in bronchopulmonary and epithelial cell lines. Environ. Toxicol. Pharmacol. 2006, 22, 97-103.

162. Kawee-ai, A.; Kuntiya, A.; Kim, S.M. Anticholinesterase and antioxidant activities of fucoxanthin purified from the microalga Phaeodactylum tricornutum. Nat. Prod. Commun. 2013, 8, 1381-1386.

163. Soontornchaiboon, W.; Joo, S.S.; Kim, S.M. Anti-inflammatory effects of violaxanthin isolated from microalga Chlorella ellipsodea in RAW 264.7 macrophages. Biol. Pharmacol. Bull. 2012, $35,1137-1144$.

164. Eichler, O.; Sies, H.; Stahl, W. Divergent optimum levels of lycopene, $\beta$-carotene and lutein protecting against UVB irradiation in human fibroblast. Photochem. Photobiol. 2002, 75, 503-506. 
165. Palozza, P.; Calviello, G.; Serini, S.; Maggiano, N.; Lanza, P.; Ranelletti, F.O.; Bartoli, G.M. $\beta$-Carotene at high concentrations induces apoptosis by enhancing oxy-radical production in human adenocarcinoma cells. Free Radic. Biol. Med. 2001, 30, 1000-1007.

166. Lowe, G.M.; Booth, L.A.; Young, A.J.; Bilton, R.F. Lycopene and $\beta$-carotene protect against oxidative damage in HT29 cells at low concentrations but rapidly lose this capacity at higher doses. Free Radic. Res. 1999, 30, 141-151.

167. Le Tutour, B.; Benslimane, F.; Gouleau, M.P.; Gouygou, J.P.; Saadan, B.; Quemeneur, F. Antioxidant and prooxidant activities of the brown algae, Laminaria digitata, Himanthalia elongata, Fucus vesiculosus, Fucus serratus and Ascophyllum nodosum. J. Appl. Phycol. 1998, 10, 121-129.

168. Li, T.L.; King, J.M.; Min, D.B. Quenching mechanisms and kinetics of carotenoids in riboflavin photosensitized singlet oxygen oxidation of vitamin D2. J. Food Biochem. 2000, 24, 477-492.

169. McNulty, H.P.; Byun, J.; Lockwood, S.F.; Jacob, R.F.; Mason, R.P. Differential effects of carotenoids on lipid peroxidation due to membrane interactions: X-ray diffraction analysis. Biochim. Biophys. Acta 2007, 1768, 167-174.

170. McNulty, H.P.; Jacob, R.F.; Mason, R.P. Biologic activity of carotenoids related to distinct membrane physicochemical interactions. Am. J. Cardiol. 2008, 101, 20-29.

(C) 2015 by the authors; licensee MDPI, Basel, Switzerland. This article is an open access article distributed under the terms and conditions of the Creative Commons Attribution license (http://creativecommons.org/licenses/by/4.0/). 